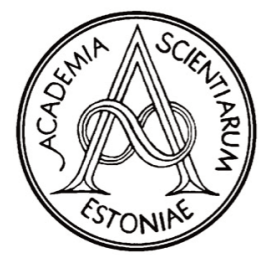

Proceedings of the Estonian Academy of Sciences, 2021, 70, 1, 19-39

https://doi.org/10.3176/proc.2021.1.03

Available online at www.eap.ee/proceedings

MECHATRONICS

AND ELECTRICAL

ENGINEERING

\title{
Implementation of Digital Twins for electrical energy conversion systems in selected case studies
}

\author{
Anton Rassõlkin ${ }^{\mathrm{a}^{*}}$, Tamás Orosz ${ }^{\mathrm{b}}$, Galina Lvovna Demidova ${ }^{\mathrm{c}}$, Vladimir Kuts ${ }^{\mathrm{d}}$, Viktor Rjabtšikov ${ }^{\mathrm{a}}$, \\ Toomas Vaimann ${ }^{\mathrm{a}}$ and Ants Kallaste ${ }^{\mathrm{a}}$ \\ ${ }^{a}$ Department of Electrical Power Engineering and Mechatronics, Tallinn University of Technology, Ehitajate tee 5, 19086 Tallinn, \\ Estonia \\ ${ }^{\mathrm{b}}$ Department of Theory of Electrical Engineering, University of West Bohemia, Univerzitni 26, 30614 Pilsen, Czech Republic \\ ${ }^{\mathrm{c}}$ Faculty of Control Systems and Robotics, ITMO University, St Petersburg 197101, Russia \\ ${ }^{\mathrm{d}}$ Department of Mechanical and Industrial Engineering, Tallinn University of Technology, Ehitajate tee 5, 19086 Tallinn, Estonia
}

Received 1 July 2020, accepted 31 August 2020, available online 25 January 2021

(C) 2021 Authors. This is an Open Access article distributed under the terms and conditions of the Creative Commons AttributionNonCommercial 4.0 International License (http://creativecommons.org/licenses/by-nc/4.0/).

\begin{abstract}
Reference implementation of Digital Twins for electrical energy conversion systems is an important and open question in the industrial domain. Digital Twins can predict the future performance, behaviour, and maintenance needs of a complex system. Today the concept of Digital Twins is not only an emulation or simulation of the physical object along with its development history but also contains much information from the respective manufacturers and services. This paper presents the current state-of-the-art of Digital Twins in relation to some interesting novel applications from different fields of electrical engineering. The objective of the paper is to give an overview of the successful application of Digital Twins in electrical energy conversion systems, such as industrial robotics and wind turbines; to discuss trends in applications like electric vehicles; and to suggest new applications, such as telescopes. Special attention is paid to the possible application of Digital Twins in faults diagnostics and prognostics of electrical energy conversion systems. Successful implementation of Digital Twins in any electrical energy conversion system diagnostics and prognostics allows for low-cost maintenance, higher utilization of the individual devices and systems, as well as lower usage of material and human resources. A SWOT analysis was performed for Digital Twin applications in electrical energy conversion systems. The latter is a useful analysis technique that explores possibilities for new achievements or solutions to existing problems and makes decisions about the best path.
\end{abstract}

Key words: electrical drives, estimation technique, mechatronic systems, diagnosis, monitoring and prognosis.

\section{INTRODUCTION}

Industry 4.0 standards [1-3] have been adopted with the aim of enhancing extensive process automation, increasing industrial efficiency and reducing the need for strenuous manual labour. After the initial investment, Industry 4.0 will lead to lowering costs due to the decreasing human-related manufacturing problems and lower operating costs $[4,5]$. And all these advantages will

\footnotetext{
${ }^{*}$ Corresponding author, anton.rassolkin@taltech.ee
}

lead the manufacturer towards increasing revenues. This is a massive change of paradigm in the industrial sector and in different technical fields, which requires change and adaptation to be applicable to the new concept of industry. The original idea of the Digital Twin (DT) [6] was to improve manufacturing processes, where the DT was defined as a digital replica of living (or non-living) entities that enable data to be seamlessly transmitted between the physical and virtual worlds. There are three main components included in the DT [7] - physical items in the real world, their virtual models, and data/view 
(telemetry) that connects the two worlds. However, some researchers (e.g. Tao at al. [8]) make a distinction between additional components such as telemetry framework integration (incl. data itself) and the service system as part of the DT. It is justified by the fact that without these additional components, the DT is mainly to be applied in the virtual world.

The DT concept was informally introduced in 2002 by Michael Grieves [9] and since that time there have been two main definitions used for the DT [10]. The first definition presents a DT as a model intended to simulate, emulate, mirror, or "twin" the life of a physical entity which may be understood as an object, a process, a human, or a human-related feature. According to the second definition, the DT is described as part of a CyberPhysical System (CPS) that interacts with the virtual entity through a communication entity.

From the simulation point of view, the DT represents the next wave in modelling, simulation, and optimization technology (see Fig. 1) [11,12]. The development of simulation technology can be very easy to trace to an example of an electrical machine design. The first computer-based numerical calculations and optimization methods were published at the beginning of the 1950s, only a few years later than the first computers were released [13]. For electrical machine design, the first code was published by Abetti in 1953 [14]. However, since that time only a few experts have been able to access the simulation and optimization methods, and this software has been applied only for very specific problems [11,15]. The first companies (e.g. ANSYS [16]) were founded in the 1960s and they have started to produce numerical solvers. These simulation tools were mainly written in Fortran programming language and expert knowledge was needed to use them. From the middle of the 1980s, with the increasing spread of workstations and personal computers, the simulation software has become a standard tool which is widely used in the industry to answer design and engineering related questions $[11,15]$. Nowadays, the simulation tools offer a more detailed, multi-domain, and multi-level simulation approach, which is the basis of model-based engineering and supports not only the product but also system-level simulations. Another trend is to apply the tools of multidisciplinary system analysis directly to the different components in order to extend the modelling and optimization capability to the full system $[17,18]$.

Still, simulation is mostly used in the development phase of the product. Extending the role of the simulation tools to the following life cycle phases of the product and supporting the operation by simulation-driven assistance is the next big trend in simulation [11]. Nowadays, there are many commercial and open-source codes available on the market, which can perform these calculations. It should be highlighted that the main advantage of the commercial solvers is that they provide user-friendly interfaces which can support and accelerate the modelling work for the simulations (e.g. Abaqus, CST Studio, ANSYS, Simcenter CAE). Commercial solvers are mostly based on lower-order finite element method (FEM) without adaptive algorithms. However, some of them (e.g. MSC NASTRAN, COMSOL Multiphysics) ensure that higher-order elements are used, up to the fifth order, and take advantage of h-adaptivity [19-21].

The DT model does not necessarily mean a spatial or visual model [22,23]. The main emphasis should be placed on process flow and relations behind it, as well as on the data entity. However, the application of augmented reality (AR) and virtual reality (VR) tools for distance simulation via the DT adds a safety layer and extra features to work with hazardous environments and remote access. The deep interaction and integration of the physical entity and the virtual object are recognized as key technologies to enhance social productivity [24]. At the same time, such an extensive complex system where the physical object interacts and is controlled by a

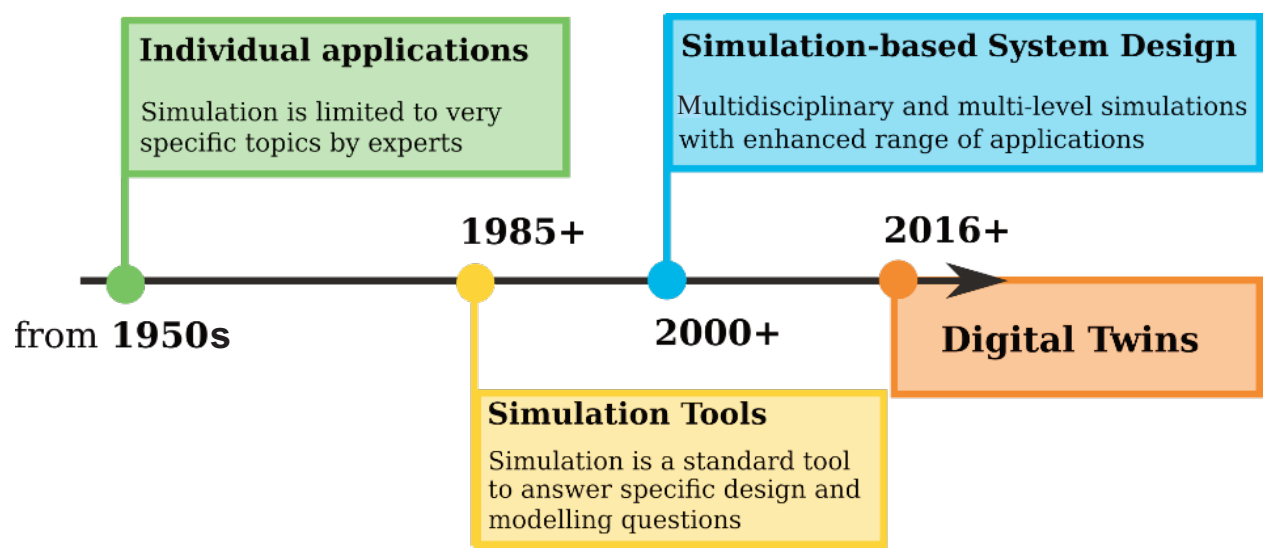

Fig. 1. Digital twins and the development of simulation technology. 
large number of distributed and networked computing elements - can be defined as the CPS [25]. However, the requirements for the performance test of an electrical machine or any other electrical energy conversion system may be quite expensive [26].

Meanwhile, the demand for a comparable virtual performance test may be optimized. The main condition is that the virtual system of the DT must behave exactly like the physical system [9]. The main drawback of CPS systems lies in the fact that they are usually time-critical [27], but real-time aspects are fundamental.

Development of this virtual representation of a real electrical energy conversion system can be integrated into a modelling process and used to support different system planning and simulation operations within the whole system. Such simulation and optimization could be performed based on the data received from the physical assets [28]. For example, the completed simulation can allow for designers to perform changes in the system concept or to tune parameters without any harm to the efficiency of the physical system. Besides, the Virtual Reality Toolkit can be integrated into the developing process to safely educate, collaborate with others, inspect and plan tasks in the DT environment on a one-to-one scale. Schluse and Rossmann [29] claim that providing the DT and using simulation for development, characterization, verification, validation, and optimization should become as natural as the hardware or software development. Simulation technology as well as Virtual Testbeds can provide key technologies for the development of intelligent systems [12,29].

This paper summarizes various DT applications for electrical energy conversion systems in different domains and suggests new applications, such as telescopes. Section 2 introduces possible DT applications for energy conversion systems from the fields of industrial robotics and wind turbines, where the DT is successfully implemented and has already been in use for a decade, through electric vehicles where the DT is claiming popularity. Special attention must be devoted to the implementation of the DT in self-driving technologies. In the future, the DT may scientifically improve the development of such a specific application as telescopes that combine unique design, control, disposition, and working in harsh environments. Virtual representation of the physical entity is very important in the DT concept. Therefore, Section 3 discusses the usage of the DT for modelling and optimization analysis in energy conversion systems for maintenance, diagnostics, and control purposes. Section 4 proposes three different scenarios of the DT usage from the fields of manufacturing, autonomous vehicles, and space observation technologies. Section 5 concludes this research and presents a SWOT analysis for DT applications in electrical energy conversion systems.

\section{TRENDY AND PROMISING APPLICATIONS OF DIGITAL TWINS}

\subsection{Industrial robotics}

Surveys conducted by Iskhakova et al. [30] among others have shown that robotics is one of the trendiest research areas. In this field, the problems of mechanical and electrical engineering, information technologies, and hardware circuits for obtaining environmental information (e.g. encoders, sensors, etc.) interact with the applied Artificial Intelligence (AI) methodology. Therefore, a control system design for complex dynamic objects contains significant uncertainty [30-33]. The main purpose of robotic systems is to make one's life more comfortable, improve working conditions, exempt one from complex work processes, and increase productivity. In recent years, robotics is experiencing a new round of development, covering also more areas of human activity in agriculture, medicine, industry, the marine sector, as well as operating under special working conditions (radiation, work in space, abnormally high or low temperatures, high overloads, etc.). This requires solving new fundamental research problems related to increasing the intelligence and reliability, also the safety of the robots. With that background, robotic systems have been one of the first applications for the DT concept.

The metric of "robot density" has been adopted by the International Federation of Robotics (IFR) to track the tipping point in modern manufacturing. For reference, in 2018 there was a global average of 74 robotic units per 10000 workers, a rise from 66 units per 10000 workers in 2015. Europe alone has an average of ca 106 robotic units, America has 91, and Asia 75 units per 10000 workers [34]. The highest robot density is registered in South-Korea with 710 robotic units per 10000 workers. For example, the United States ranks 7th with 200 units, Germany holds the $3 \mathrm{rd}$ place with 322 robotic units for the same number of workers, China is in the 21 st place, and Estonia ranks 38th with 11 robotic units per 10000 workers [34].

Industrial Robot (IR) is a widely used equipment in today's manufacturing and it is quickly becoming an important technology that helps enterprises to innovate while improving business performance [35]. Three different approaches (methods) of integration and programming are mainly used for the IR to automate the industry [36]:

- Offline method. Commonly, every large manufacturer has its own software tool for programming in the IR. Every step can be simulated and performed, then downloaded to the robot controller.

- Manual method. The usage of a flex pendant by the operator gives an intuitive and real-time feeling of what is happening with the system. 
- Online method. The robot controller is connected to the external control unit as a camera or sensor equipment, which enables one to affect robot movement online, interrupting, or re-writing the task performed by the robot [37].

Virtual Testbeds (VT) are widely used in IR systems. In these systems, the complex technical solutions and interactions are implemented in a simulation before commissioning the real system. At the same time, the DT is presented as a virtual replacement of a real physical entity. Consisting of virtual representations and communication capabilities, the VT and the DT lead to a new kind of Experimental DT (as presented by Schluse and Rossmann in [29]), which is breaking new ground in the simulationbased development and operation of complex technical systems. Moreover, Virtual Testbeds and DT simulations can enrich the above-mentioned traditional programming methods for IR programming by various combinations and hybrid modes, e.g. by allowing to re-program robots online by hand guidance or sending new command lines, while the initial robot path routine was made in offline mode by a brand-offered or generic software package [36].

\subsection{Electric vehicles, including self-driving vehicles}

Electric Vehicle (EV) design is an interdisciplinary task. It is a mixture of mechanical, electrical and software engineering [38]. According to Statista [39], there were under 3.3 million battery EVs in use globally in 2018, and almost 1.5 million battery EVs were sold worldwide in 2018. At the beginning of 2020 in Estonia there were 4442 vehicles with electric propulsion [40], which is only $0.66 \%$ of the total number of vehicles (more than 676 thousand units). For example, the cumulated number of all new EV registrations in Germany [41] has reached 200 thousand units and the corresponding figure in the Russian Federation in 2020, according to Autostat [42], was 6 thousand units.

The EV is a complex system, which requires an accurate mathematical description for monitoring and validation [43]. Nowadays, much attention is paid to the different parts of EVs. The economic and technical efficiency are the most important factors to estimate the drive quality [44]. The mostly examined quantities are the cost of capitalization, the power density of the drive (resulting from the system size and weight), and the reliability of the drive $[43,45,46]$. Most of the actual EV testing techniques are mainly based on physical sensors and oriented to the more steady-state applications [47]. Research has covered but a few aspects of monitoring techniques, reporting only on dynamic operating regimes $[48,49]$. Various test benches [50,51] and prototypes $[52,53]$ are used to validate the concept before its industrial/practical application. Detecting and monitoring the critical spots or hotspots in the electric propulsion drive system are the key factors enabling the whole EV system to perform effectively and safely. Development and implementation of the concept of the DT and virtual sensors [54] will help to provide a brand new approach for measurement and estimation of the steady-state and the transient state of the EV electric propulsion drive system [48]. Such a DT for the EV propulsion system will be able to recommend approaches to the drive regulator tuning, control looping, sensor allocation, and feedback arrangements [44].

The rapid development of various object detection sensors (e.g. LiDARS, radars, cameras, etc.), together with wireless communications, has made significant advances in driver assistance systems and autonomous vehicle (AV) development. The concepts defining the DT should strongly consider vehicle autonomy. Some of the fundamental demands imposed on the AV include obeying the traffic rules, the possibility to travel long distances without traffic accidents, avoiding traffic congestions, and the ability to perform without human interaction [55]. There are 16 trillion automobile kilometers driven each year worldwide [56] under various environmental and traffic conditions that generate millions of unique situations in which AVs could fail. The highly intelligent systems of an AV should take into account a broader range of information about the current road situation and regard the car itself as a human driver. To enable the AV to handle adverse driving conditions such as rain, snow, and dirt on the road, etc., the control algorithm must be able to recognize roads within a tolerable margin of error with the help of measuring instruments [55,57].

Kalra and Paddock [58] have presented a statistical analysis of the mileage that an AV must travel in order to produce precise estimates of the AV crash rate based on observational data. To demonstrate that the fatality rate of the fully autonomous vehicles is 1.09 fatalities per 100 million miles (with the reliability of $99.9999989 \%$ within the probability of $95 \%$ confidence level), the vehicles would have to be driven 275 million failure-free miles (ca 440 million km). With a fleet of 100 AVs being test-driven for 24 hours a day and 365 days a year at an average speed of $25 \mathrm{mph}(40 \mathrm{~km} / \mathrm{h})$, this would take about 12.5 years [58,59]. With the speed limit of $20 \mathrm{~km} / \mathrm{h}$ for ISEAUTO [60], that will make 25 years. Glaessgen and Stargel [61] discuss the possible application of the DT for EV certifications. The DT paradigm is presented as a longterm vision, comprising the ability to fully understand degradation and irregular events in the EV with regard to current practices for certification, fleet management, and sustainment. Shubenkova et al. [62] have presented and analysed a possible application of the DT in tracking the data of failures during the logistic process and the indication of failures of separate vehicles by the example of 
the KAMAZ truck. The predicted number of failures obtained from the developed DT in comparison to real shortcomings was in the range of $10 \%$, which is a compelling improvement. The ambition of Brunner et al. [63] is the development of an adaptable, modular simulation framework to analyse complex issues of autonomous driving with a view to improving safety performance in complex urban traffic scenarios. Such a simulation framework will take unanticipated safety impacts of mixed traffic into account. These are difficult or sometimes unreasonable to evaluate and address, and to determine possible solutions (e.g. advanced prediction indicators and algorithms) for road users.

\subsection{Wind turbines}

The world market for wind turbines (WTs) is still growing. In 2019 new wind power turbines with the summary power of $15.4 \mathrm{GW}$ [64] were installed in Europe. This is $27 \%$ more than in 2018 but $10 \%$ less than in the record year 2017 [65]. For example, in February 2020 , of the total 45.13 TWh generated by Germany's power sector, $20.80 \mathrm{TWh}(46 \%)$ was generated from wind energy sources [66]. In the same period in Estonia, 106.59 GWh was generated from wind energy, which is $31.6 \%$ of the total generated energy of $336.70 \mathrm{GWh}$ [67]. The European Commission states that Europe needs up to $450 \mathrm{GW}$ of offshore wind by 2050 in combination with onshore wind systems. It could be one of the main sources of power generation systems. $450 \mathrm{GW}$ would meet $30 \%$ of Europe's electricity demand in 2050. This will require an increase in the number of WT staff and, consequently, there will be an increase in the cost of electricity. This issue could be addressed by using the DT to analyse the operation of a wind farm in normal mode and in fault detection mode.

The DT concept of the WT promotes condition-based monitoring over the scheduled maintenance routine of any single WT, leading to more effective use of resources. Such a concept will, in turn, reduce the use of energy, human and material resources. The maintenance of offshore wind farms is a huge resource-consuming operation. Appropriate maintenance also reduces the stress on the materials and, thus, increases the lifetime of electrical energy conversion systems, resulting in better usage of the resources needed for manufacturing them [68] (such as iron, aluminium, copper, and rare earth ores, among others). WTs and farms generate an enormous amount of operational data and data analysis. It is needed not only for a PC hardware base but also for a special software solution - the CAD system. The following software is used for WTs: SCADA [69], ANSYS [16,70-72], Wind PowerUp [73], Seebo's application [74], PTC [75], and many other private solutions.
The DT concept applied to the WT area could undertake the following tasks:

- Find the best solution in the design system and prove it in a testing procedure;

- Find the best solution in the position of the WT, which takes into account wind speed, waves, temperature, etc.;

- Create a correct device imitation model including a mathematical model for the WT with blades, which is based on the data from the real object;

- Develop reliability models collecting data from sensors;

- Accumulate WT service data for models dealing with fault detection in electronics and subsystems of mechanics;

- Develop risk assessment models;

- DT for small-scale wind turbines (e.g. [76] or based on Magnus effect [77]) could help to develop a predictive model for electricity cost in distributed energy systems.

Specific models have been built for the five-dimension DT according to the DT modelling methods explored by Imaie et al. [78], where the WT is taken as an example of sophisticated equipment [79]. The physical entity of the above discussed WT consists of separate subsystems and sensors. The energy conversion subsystems are represented by different parts of the WT, such as blades, electrical machine (generator), gear, and yaw system [69]. The components of the DT model for a wind turbine are shown in Fig. 2. Mounted sensors are used to track the electrical machine's temperature, mechanical vibrations, and power output. The digital entity of the WT consists of a geometry model, physics model, behaviour model, and rule model.

Successful implementation of the DT concept for the WT is shown by Pargmann et al. [80]. The DT is based on a combination of big data with an analysis algorithm to optimize technical decisions. DT topology consists of sensors that are included in power converters and the Raspberry Pi, which collects data from sensors and sends it through the MQTT-protocol to the cloud by the IoT-interface. Based on this technology, the DT includes several wind farms in different countries working in parallel. The applied cloudbased technology has a $40 \mathrm{~ms}$ delay time in an environment of 2000 sensors.

The DT topology of the WT generator is discussed by Ebrahimi [71]. This DT generator model is based on a multidomain physical model with probability functions that include harmonic analysis of the currents, voltages, and magnetic fluxes. The Neural Network (NN) approach was used to find the best DT generator prototype in the context of epistemic and probabilistic uncertainties such as electromagnetic, vibration, and thermal processes. Similar work on a DT generator model but based on a 


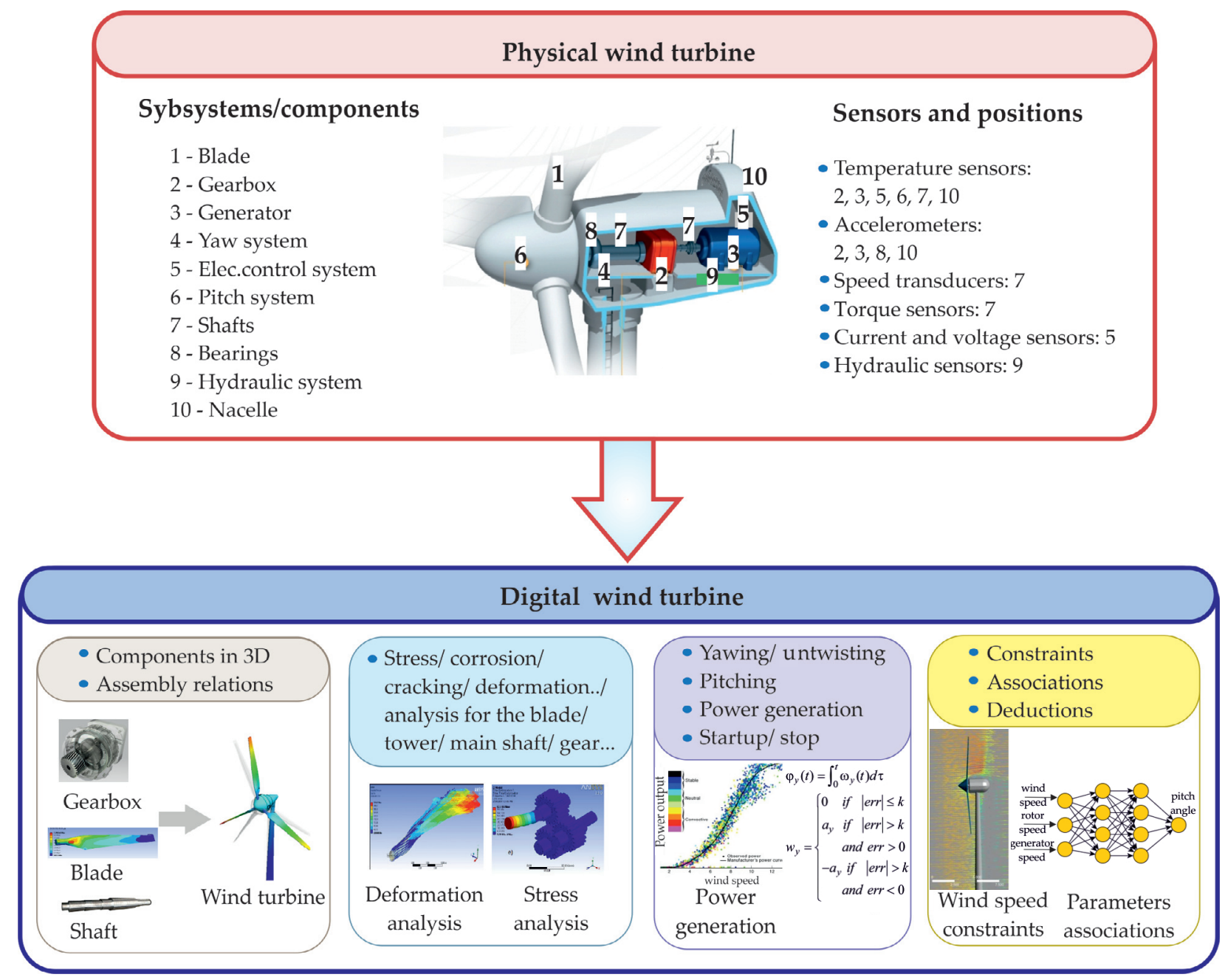

Fig. 2. Modelling of DT components for a wind turbine.

finite element analysis of the linear winding process is presented by Weigelt et al. [72]. The research introduces a winding model that consists of material and geometry, as well as the course of the caster angle and its variations due to filament winding.

$\mathrm{NN}$ algorithms are also used for improving short-term wind power prediction, as shown in [81]. The 24-hour prediction accuracy of wind power was improved considerably, using mutual information and providing an irrelevancy filter for reducing the input dimension by eliminating irrelevant candidates and using more effectively an imperialist competitive evolutionary algorithm for NN training. Together with real-time digital simulators [82], the DT approach may be successfully implemented for WTs that are used in microgrids.

\subsection{Telescopes}

Such an electrical energy conversion system as the telescope is a very specific application that combines unique design, precise control, specific disposition, and often harsh working environment. Telescope axes have a multi-mass construction, and the compound parts have a large difference in mass (from several tens of kilograms to several tens of thousands of kilograms) with non-rigid connections between the parts [83]. The creation of a DT for a telescope might be another rewarding task for researchers working in that field. The traditional flowchart for developing the telescope model is presented in Fig. 3.

There are only a few models for the modal analysis of telescopes available nowadays [84-88], but these provide some inspiration for the creation of virtual models. The practical development of the DT for the telescope is interesting due to the development of a remote-control system, as such quantum-optical complexes are placed in remote uninhabited areas (usually in high mountains). Another application benefitting the telescope by using the DT is the prediction of the non-linear behaviour of the telescope related to action disturbances on the system, such as wind [89] and internal forces (e.g. cable pulling, 

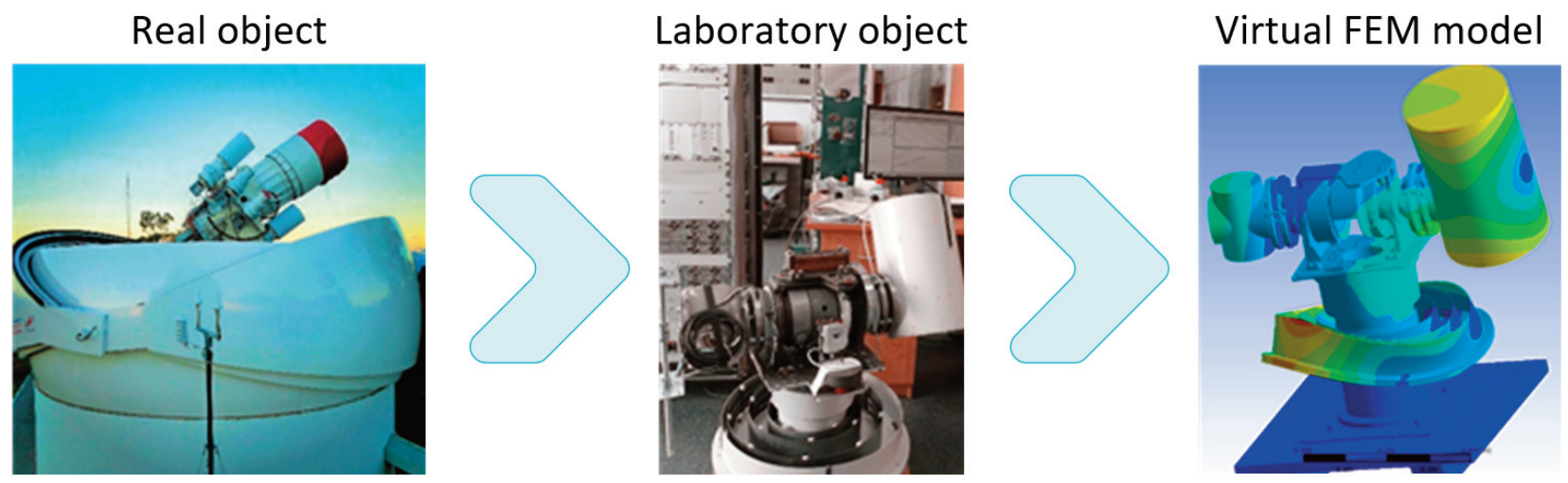

Fig. 3. From the real telescope to the virtual model through the prototype.

dry friction torque, etc. $[83,90,91])$. Such a DT could be useful if the telescope is required to be used in intermittent duty cycles. The application of the DT approach may help researcher teams to work virtually and remotely, away from the real objects. The first concepts are currently in the initial phase of discussion [92].

\section{METHODS}

\subsection{Numerical modelling and optimization}

Numerical modelling and design optimization of systems and devices are essential parts of the DT concept, as this concept refers to a comprehensive physical and functional description, as well as to the database of the product. It contains all of the experimental and design calculation data which could be useful for supporting the autonomous manufacturing systems at any time during the life-cycle of the product, making it possible to respond to the unexpected events in a very short time [11,12,78,93,94].

In the future, the DT as a complex virtual product can reflect the whole life-cycle process of the corresponding physical product. These pieces of information from the product design and its lifelong performance can assist in making more economical and environmentally friendly designs in the future. The idea of the life-cycle cost assessment of the products is not new. At the beginning of the 20th century different power transformer designs were made for coal and water power plants to take different utilization factors of the different power plants into consideration [95]. The first general concept of the life-cycle analysis was published by Dean in 1950 [96], and still today there are many different approaches published in the literature $[13,78]$.

Although taking these factors into account at the beginning of the product design phase, it is not sufficient to use proper simulation tools but these tools should work together with different optimization solvers. Finding an appropriate solver for the optimization task is not straightforward due to the "no free lunch" theorem of mathematical optimization [97], which in a very broad sense states that when the performance of algorithms averages over all possible problems, no algorithm performs better than all the others. This means that for a specific problem one has to find the most appropriate optimization solver. In the case of real-world industrial problems the goal is not to find the cheapest solution or the global optimum of the task, but the new trend with regard to optimization solvers is to find a robust optimum solver for the task $[20,98]$, which is intolerant of the manufacturing tolerances, as shown in Fig. 4. The red dot ( $g$ ) denotes the global optimum if the target is to minimize the value of $f(x)$. However, a more robust solution is given by $\mathrm{r}$ (denoted by the green dot), in which the sensitivity $(d r)$ is significantly smaller than the sensitivity $(d g)$.

Burnett [99] has presented a DT concept as a resource for design research. The project aims to visualize live data as it relates to the physical product in the wild, enabling contextual inquiry and supporting data exploration.

Cerrone et al. [100] have successfully implemented asmanufactured component geometry, its effectiveness, and

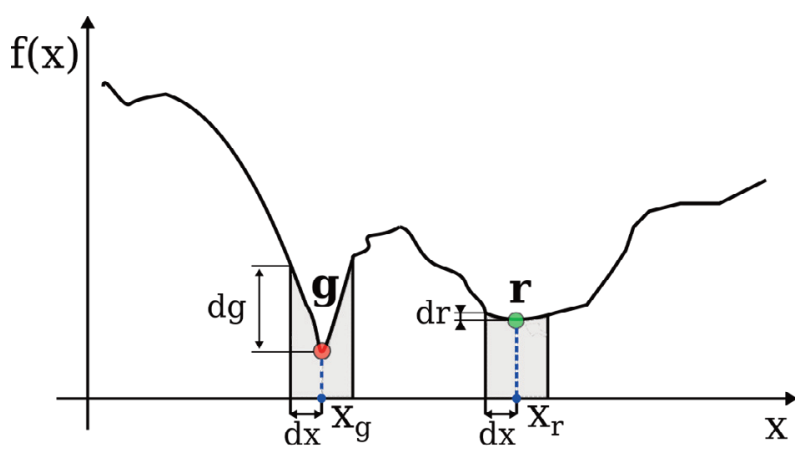

Fig. 4. One-dimensional explanation of optimality versus robustness. 
applicability to small-scale scenarios. The DT concept applied in their study has been verified in two steps. First, after the conventional modelling and manufacturing some product defects were detected (crack-path), and this was the reason to consider as-manufactured specimens. The second model was developed to test the computational model's performance in determining the physical quantities. It is worth paying attention that the resulting variation in behaviour was not accidental, but the expected consequence of as-manufactured geometry and material model improvements.

\subsection{Energy optimization}

It concerns the principle of electric energy conversion systems' optimization based on more effective usage of various industrial machines while re-programming or readjusting them. DT technology with an integrated control mechanism can be used to modify, optimize, and deploy programming codes of various applications in the simulation. Enabling synchronization between real and physical assets can be used to upload a new optimized code of the machine directly to its controller in a matter of seconds, not spending valuable time on the machine [101]. Thus, in this way a machine is being re-programmed while still proceeding with its daily duties and the stand-by time of the machine is being decreased, resulting in energy cost savings.

Another part of energy consumption optimization allows for more energy-efficient applications of electrical energy conversion systems in a wide dynamic range of speed and power by combining the system approach with the optimization of semiconductor devices. Such a system optimization may place more stress on the separate components of the whole system in different operation modes, which can cause a higher failure rate of parts under stress [102], and more attention must be addressed to system diagnostics and maintenance. Zhang et al. [103] have introduced a methodology for constrained, robust parameter optimization, which means not only minimizing the energy consumption but also providing a set of constraints like product quality, productivity, delivery time, etc. The methodology also includes scheduling optimization which can virtually predict the time needed for completing tasks, as well as equipment upgrading through analysing the previous situations and historical energy consumption.

A case study by Karanjkar et al. [104] presents the use of an IoT-driven DT for energy optimization in a printed circuit board (PCB) assembly line. Based on the insights gained from the data collected over several days, a buffering-based solution for improving the energy efficiency of the line is proposed. The evaluation of its impact was made by using simulations of the DT. The results show 2.7 times higher reduction in energy consumption.

\subsection{Maintenance and service}

Sivalingam et al. [69] describe and demonstrate a methodology involving the DT, which helps to predict damage accumulation in offshore WT power converters. It is shown how to find optimal maintenance decisions based on the DT technology platform, using data from virtual sensors [105]. The virtual sensors were created by employing aeroelastic models and the FEM. The minimum input data that were used are wind speed, environmental temperature, blade yaw angle, and electrical power in the system. The developed DT deals with the risk of failure of one of the modules. It can estimate the probable symptoms of equipment malfunctions and the remaining life.

Cabling is an important part of any electrical energy conversion systems. The main goal of the research by Oñederra et al. [70] is to provide a DT for the cable system, which enables to calculate the cable ageing time through the cable current. The most significant result of the study is the obtained curves that indicate the cable replacement time. Such a developed model for the cable system of the WT could be extended to the DTs of the whole wind farm.

Kandukuri et al. [106] suggest using the DT for fault detection in the WT, especially in electrical pitch drives. Three-phase motor current measurements are used to detect a fault and after that a support vector machine is employed.

\subsection{Diagnostics}

As to the reflectivity test, the idea that a company is maintaining a link with its product after it has left the factory is very much a twenty-first-century concept [9]. Different methods of fault detection are used today in the electrical conversion system and operation monitoring. The recent developments of the fault diagnosis and process monitoring methods $[107,108]$ can be categorized as data-driven and model-based approaches. In the datadriven method, the required data is extracted directly from the recorded (collected) data, utilizing appropriate input and output information. For example, methods based on time-frequency signal post-processing are used with current, vibration, and acoustic signals to detect the diverse symptoms of electrical machine failures. The described methods are generally used for the faults diagnostics of electromechanical energy conversion systems [109], which is a key component in EVs and in the IR.

The model-based methods require in any case a physical and mathematical description of the system. 
That technique can be applied only after the development of the system model based on physical relations. And only after the development of the physical relations based on the behaviour model, a model-based technique can be implemented. Literature analysis in this field [110-112] shows that the systematic use of mathematical processes and signal models, identification, and estimation methods provide a tool for fault detection and diagnosis. The VT presented in Subsection 2.1 may play a significant role in fault detection and diagnosis, therefore it is reasonable to direct attention to DT approaches. This is facilitated by the fact that closed systems or modern plug-and-play components focus on expanding functionality through the use of software solutions. Thus, the functionality of the software is becoming the main factor of choice since users expect modern controllers to perform all the necessary tasks without any additional configuration. This means that less money will be spent on individual components, and more money will be invested in software solutions.
Electrical energy conversion systems are subject to different faults, the consequences of which depend significantly on the fault location $[113,114]$. In Fig. 5, the basic faults occurring in the electromechanical energy conversion system are listed and illustrated.

Electrical machine faults certainly depend on the type of the electrical machine, although the faults can be divided into two categories: electrical and mechanical faults. The type of the electrical machine determines the possible types of faults, e.g. the squirrel cage faults [115117] are typical for induction motors and the danger of demagnetization [118] occurs in permanent magnet synchronous machines.

The most frequent mechanical causes for electrical machine and transmission failures are bearings related failures and these can usually be detected by increased noise and vibration. According to Kudelina et al. [119], the reasons for bearing failures can include different environmental or manufacturing factors such as overload, wrong emplacement, material fatigue, bad lubrication,

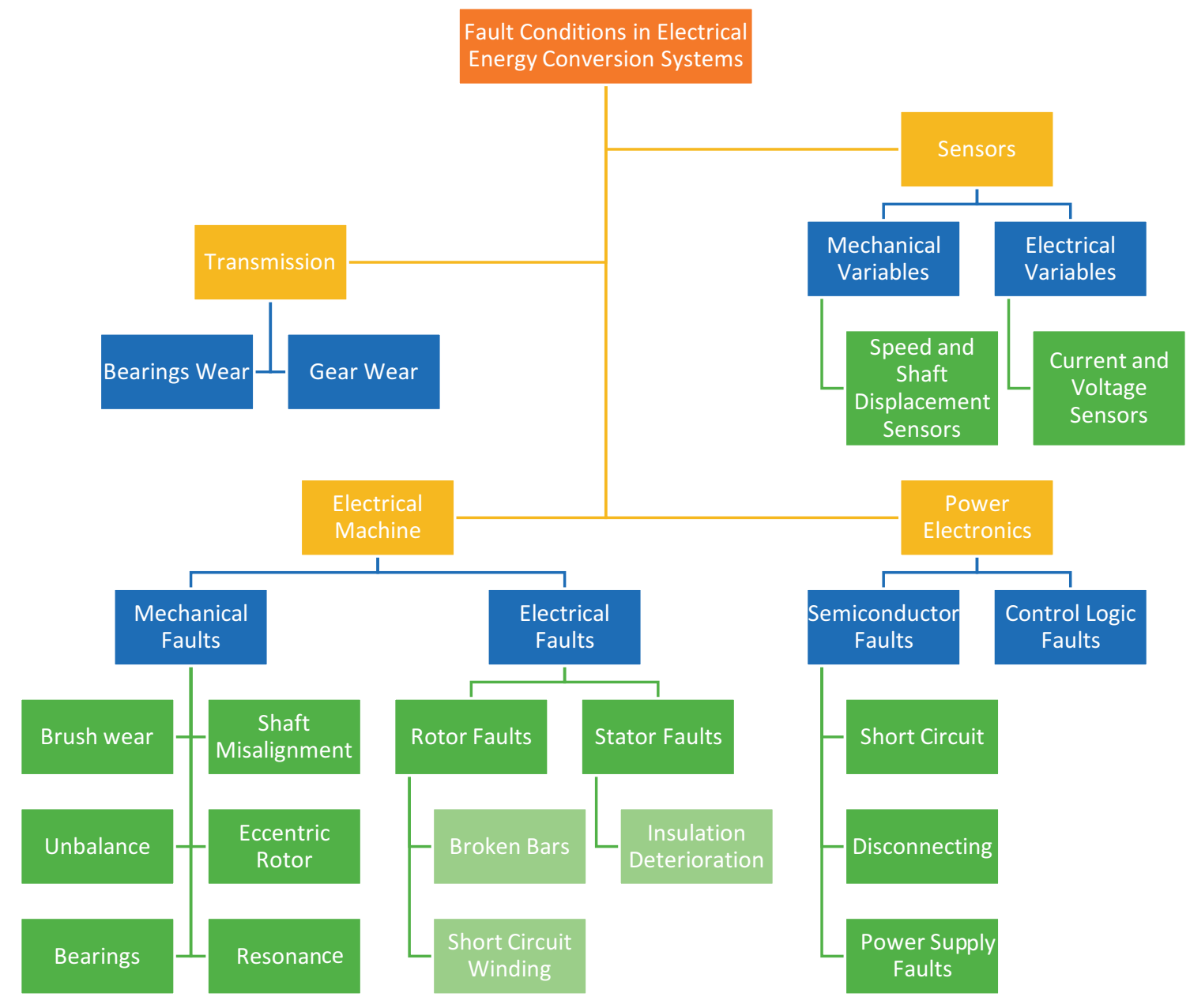

Fig. 5. Possible fault conditions in electromechanical energy conversion systems. 
environmental pollution, bearing and/or shaft currents, etc. Nonetheless, unbalance, eccentricity, brushes, and shaft related faults may also cause serious damage to the system.

With all the variety of failures in electromechanical energy conversion systems, power converter faults make up about $80 \%$ [120]. According to Yang et al. [121], the main faults in power converters are as follows: DC-link capacitor $(30 \%)$, printed circuit boards (PCB) $(26 \%)$, power semiconductor devices $(21 \%)$, soldering defects $(13 \%)$, etc. (e.g. sensors). All these faults result in the performance degradation of an electromechanical energy conversion system or possible unplanned stoppage of the system. The semiconductor device faults can be divided into three categories: short circuit faults, open switch (disconnecting) faults, and power supply related faults.

The main principles of the DT shown in Subsection 2.2 have an immediate and critical application to fault detection in the WT. Ruiming et al. [122] have proposed a method for detecting WT defects based on SCADA data, using correlation and cross-correlation analysis approaches. They have used the DT for the WT represented by complex multi-node networks based on sensor data, and special markers were proposed to alarm fault signals. Thus, such an approach allows for detecting faults in the early stage.

Tao et al. [79] present faults in two categories gradual and abrupt - and suggest a new approach for prognostics and health management driven by the DT based on prediction algorithms concerned with data about faults. The DT consists of the traditional physical-virtual model of the WT: design, production, additional data (dealing with environmental disturbances), and services.

Smart health monitoring technology in the DT for floating offshore wind turbines is presented by Kim et al. [123]. This research addresses the detection of damage in blades and towers of WTs. Signals from sensors were used for operation modal analysis and were confirmed by the FEM analysis. The main benefit of that research is structural health monitoring, including wave modelling for offshore WTs. Tao et al. [124] have defined a concept for WT prognostics and health management, and suggest several algorithms based on the $\mathrm{NN}$ and the co-evolutionary approach to predict faults and use them in the DT. An identical strategy may be applied to any other electrical energy conversion system, as shown in Fig. 6. The main objectives in this research are the gearbox and the yaw system due to their frequent breakdown. The NN was created for the gearbox to detect the cause of faults (tooth wear/tooth fatigue/tooth breakage) by using input data from the real entity (frequency center, frequency variance, mean square frequency) and virtual gearboxes (maximum contact stress, maximum bending stress, number of gear meshing).

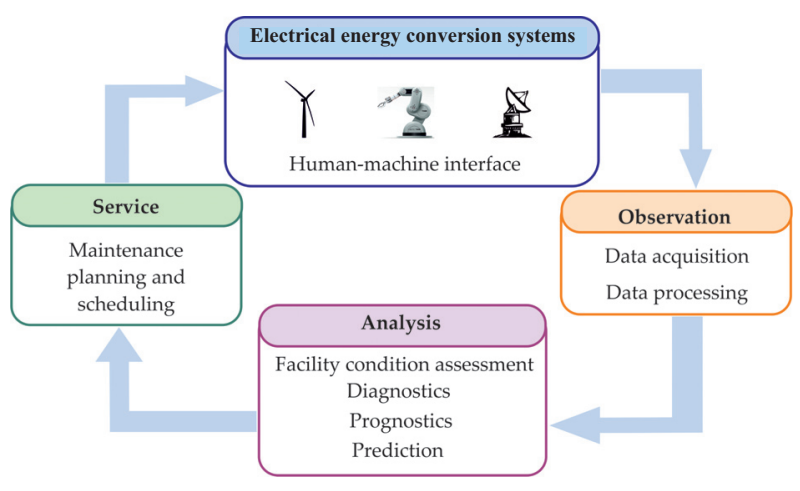

Fig. 6. Structure scheme of prognostics and health management in electrical energy conversion systems.

\subsection{Control principles of electrical energy conversion systems}

Combining machine learning with the DT concept will help in assessing the performance of the electrical energy conversion systems. Various interpretations of Kalman filters, transient models, decision trees, and different NN architectures are the most widely used tools. The main procedure for any $\mathrm{NN}$ design method includes two stages. The first stage concerns the training process, the part of the signal data received from the real physical entity or its reduced copy (test bench) combined with DT performance data and used to train the network. Moreover, some data is used to validate the training operation. The second stage consists in using the trained $\mathrm{NN}$ to analyse the performance of the electrical energy conversion system and to control the physical entity's operation mode through the observed data. After some time, when the NN algorithm has already determined relations in the complex system and localizes them, it can predict the behaviour and give suggestions for the operation mode of the real electrical energy conversion system based on the online DT. A drawback of such a NN design method is the significant amount and high-quality requirements for the data used to train the NN. Another issue is the high resolution of the sensors used for parameterization and performance evaluation of the complex system. Such sensors require a full communication band to transfer data between the sensors and the virtual entity of the DT. Figure 7 shows the path of the conversion of data collected from sensors.

The important part of the DT is algorithms that transform the obtained data to the virtual model. Taking into account the fact that data could be unstructured, Lermer et al. [125] suggest using not only the NN but also fuzzy logic for the DT development. Procedures and techniques described in that paper result in the imple- 


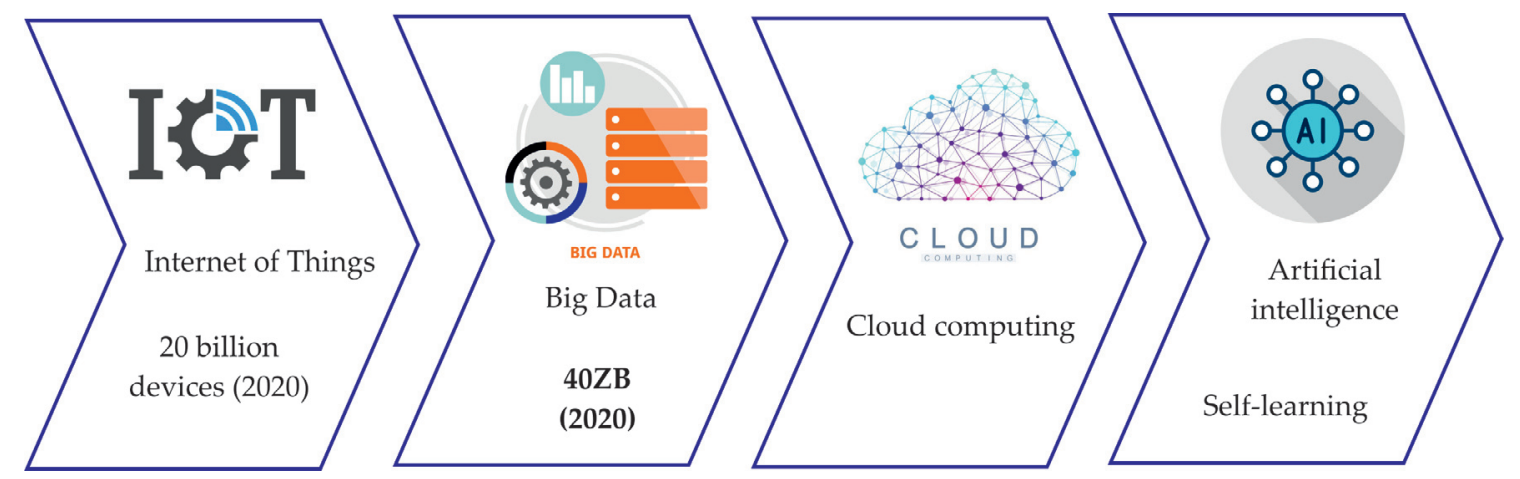

Fig. 7. The path of the conversion of data collected from sensors.

mentation of the DT and show the opportunity to receive live predictions.

\section{IMPLEMENTATION EXAMPLES}

\subsection{DT for IR in Smart Industry environment}

The main goal of the performed research on the DT $[78,126]$ has been to develop a framework for the connection between the physical and virtual equipment. Based on recent developments, an immersive simulation was designed and implemented by following the principles of Industry 4.0. A particular aim was to exploit the DT concept not only in simulation by the usage of realworld data feed but to generate a DT creation methodology for dual-way synchronization. This type of connection enables in particular use cases to manage and control the Industrial Robot from the simulation in real time. A substantial part of the study analyses the developments and approaches in the field of the Smart Industry and combines research with various IR programming methods, the DT concepts, virtual reality technologies, the Robot Operation System (ROS), and the Industrial Internet of Things (IIoT).

Moreover, during the investigation of safe and collaborative programming methods for the IR operator [127], it was discovered that there was a lack of methodologies for smart simulations in regard to dual-way simulation. A methodology architecture and framework for dual-way telemetry data synchronization of the DT would enable safe and effective ways for the adaptive industrial robot algorithms. The related architecture can monitor and optimize data feeds from various sensors, giving a robot the ability to adapt to the situation, avoiding collisions with objects and operators. Scenarios for use cases based on the presented synchronization architecture can enable safe teleoperation of the real industrial equipment from remote distances by the usage of developed virtual reality interfaces, which enables the person to rather think about the final aim than focus on the industrial process. An experiment conducted during the studies was performed in an immersive development environment (Fig. 8) based on the example of flexible manufacturing systems and the robotics research laboratory.

A base, an open-source solution for fully synchronized DT environments, was developed. It can be used as a base for similar environment re-creations and connections through a universal middle-layer. Besides, the developed environment supports multiplayer mode by providing possibilities for simulation and education $[128,129]$ of the new operators without interfering with physical and dangerous equipment.

\subsection{ISEAUTO project}

AVs are gaining popularity nowadays and special attention is paid to the systems that are able to improve the control and tuning possibilities of the EV, such as the driving suitability, mobility of the vehicle, cruising stability and ease, parking accuracy. ISEAUTO is a last-mile bus that operates on the campus of Tallinn University of Technology (Tallinn, Estonia) and in the city of Tallinn. ISEAUTO mainly operates in parking and pedestrian areas, which means that an obstacle should be detected at a very short distance. For that reason, the following sensors are used for observing the environment, as well as for mapping, localization and navigation process in the first prototype: LiDAR Velodyne VLP-16 (2 pieces); Ultrasonic sensors, front and back ( 8 pieces); Ultrasonic sensors, door side (6 pieces); Short distance radar; Cameras (8 pieces); RTK-GNSS; IMU sensor [52]. The body design of ISEAUTO and the location of sensors is shown in Fig. 9.

ISEAUTO, as the reconfigurable platform developed for research and education, covers all the needs for 

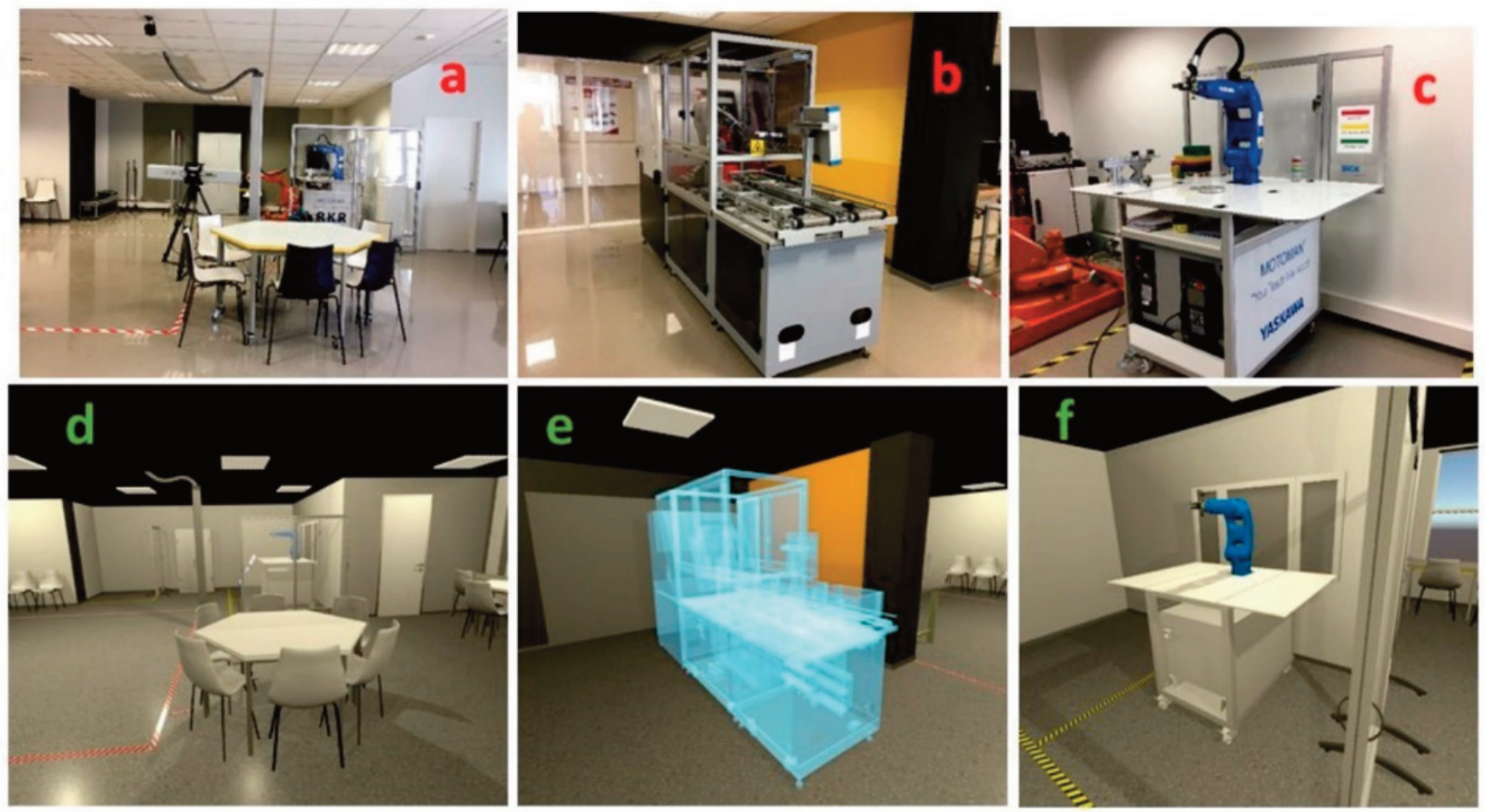

Fig. 8. DT for the Industrial Robot in a Smart Industry environment (a, b, c - real entities; d, e, f - virtual replicas).

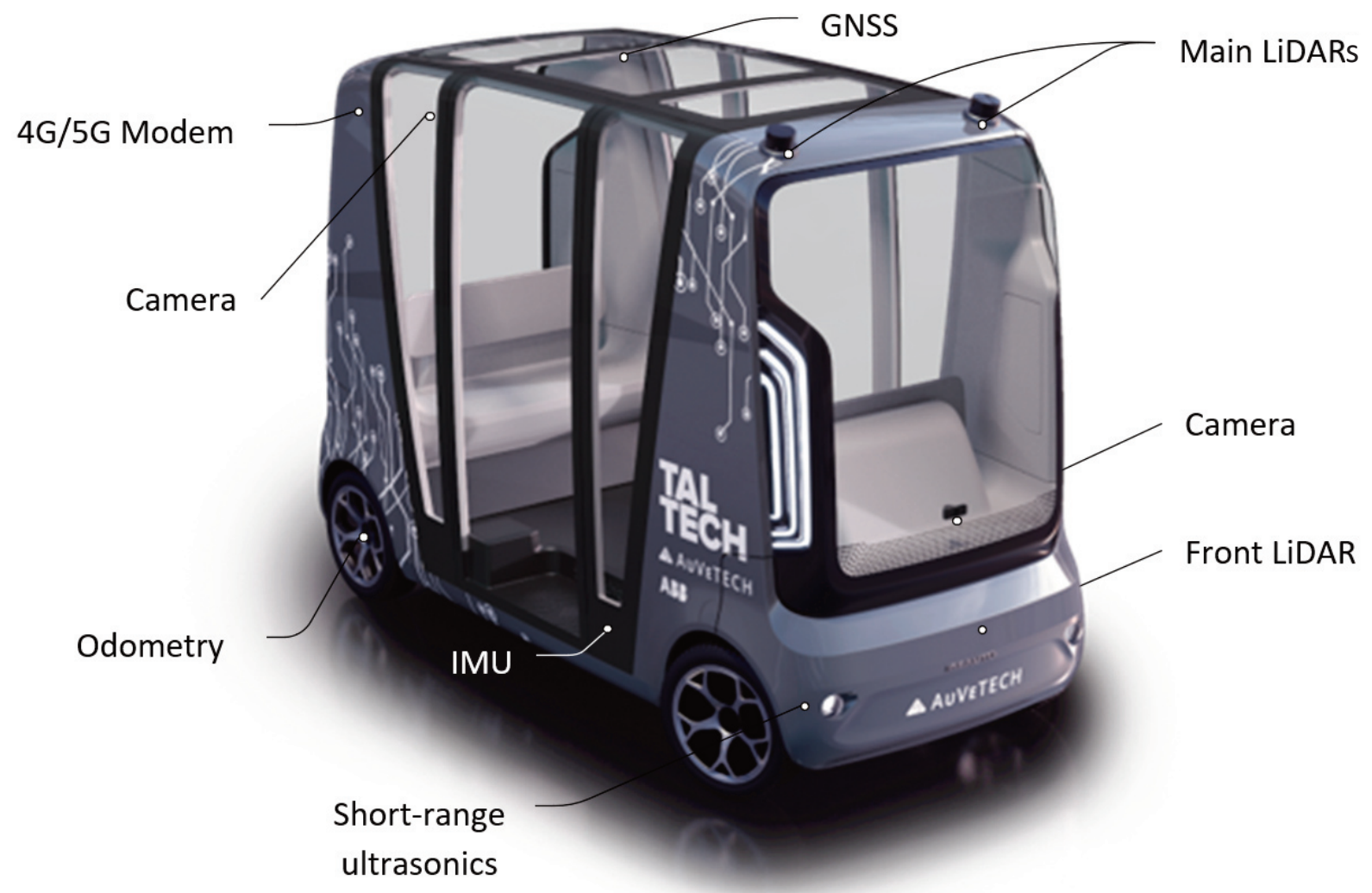

Fig. 9. Location of ISEAUTO's last-mile bus sensors. 
developing and testing the DT. Development of virtual entities for different components of an EV (incl. battery, traction motor, gearbox, transmission, etc.) and the related reduced models of these components (testbeds) will be the first goal. The developed entity will assist in the construction of the DT for the propulsion system of an AV. Such a DT for the AV will promote the implementation of the Industry 4.0 concept, secure EV/AV tests, improve AV application, and provide opportunities for new business models. "Digital twin for propulsion drive of an autonomous electric vehicle" is an ongoing project by the authors. The main goal of the project is to develop a DTconcept-based prognosis and control platform for the performance estimation of the electric propulsion drive system. These requirements for achieving the main goal are divided into several subtasks and objectives [44]:

- Development of several reduced models of these components (testbeds) that will be used to develop the DT for the propulsion system of ISEAUTO;

- Development and implementation of the concept of Virtual Sensors (VS);

- Development of an AI-based system that allows for the usage of the VS in controlling the electric propulsion drive system of ISEAUTO.

\subsection{Telescope for monitoring space debris}

A potential promising application of the DT in telescopes may be related to space debris, which is an issue gaining popularity because of the development of world communication networks and space exploration $[130,131]$. The DT may be very useful in debris tracking and detecting satellites that have stopped functioning, and as a consequence, in calculating safe trajectories for already operating or new satellites. Researchers from the Faculty of Control Systems and Robotics at ITMO
University have developed high-precision electric drives that rotate the telescope (Fig. 10).

During more than a half-century of the satellite's history, there have been almost 6 thousand space missions [132], and the majority of them related to the planet's orbit. Based on Roscosmos statistics [133], there are currently more than 2000 pieces of debris bigger than $10 \mathrm{~cm}$ spread around the Earth's orbit. This fact indicates that the Earth's orbit is full of worn sub-parts and unused satellites. Due to the debris in the space, like on the Earth's surface, casual accidents happen, satellites collide.

Telescopes are very similar to the IR, they require very precise control of the trajectory, which should communicate and take the information from the central computer or special equipment into consideration [134136]. The main problem in such quantum-optical systems of tracking is that they are installed in places with a large number of cloudless days per year, i.e. most often in the mountains, not easily accessible places for specialists. Thus, much of the specialist working time is spent on moving to these locations in addition to tuning the control systems and removing any faults. DT telescopes could help to predict any faults and fix them by remote control.

\section{CONCLUSIONS}

A SWOT analysis based on the cases discussed in this paper and performed for DT applications in electrical energy conversion systems is presented in Table 1 . The main conclusions based on the SWOT analysis may be viewed as the most important ways the DT can contribute to electrical energy conversion systems. For that purpose, it is necessary that a service dataset is made available for further development and research. DT assets enable system designers to view the behaviour of the system in real time
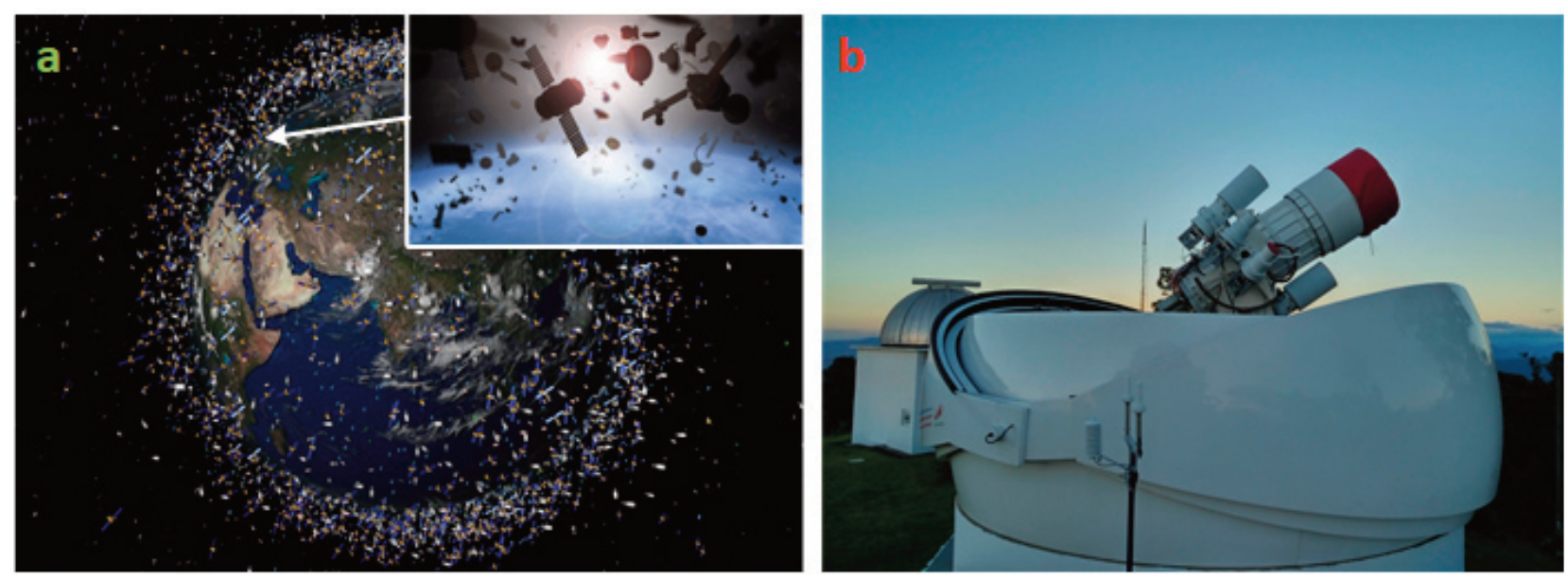

Fig. 10. Space debris (a) and the telescope's (b) electric drive developed at ITMO University for monitoring space debris. 
Table 1. SWOT analysis of the DT application in electrical energy conversion systems

Strengths domains may be represented in one DT;

- DT is a useful solution when any service, e.g. analysis, optimization, tuning, etc., cannot be performed online;

- Appropriate feedback to the customer or connected service;

- Better insights into the objects of the electrical energy conversion system and better decisions. $\frac{\text { Opportunities }}{\text { - } \quad \text { Reduction of the operating cost of the electrical energy }}$ conversion systems;

- Extended life of the equipment and assets;

- New functionalities can be connected to devices or systems;

- Different data can be combined, which means that new factors can be detected;

- Novel control interfaces;

- Flexible data visualization;

- Immersive experience with augmented reality and virtual reality;

- $\quad$ Final model-based design.

and apply practical knowledge gained from the real-world system. By the application of the DT, hybrid modelling and analysing methodology can be developed that will contribute to the computational modelling and simulation of complex problems that arise in numerous multidisciplinary applications, such as electrical energy conversion systems. The DT provides a big potential for better observing of electrical energy conversion systems and driving better control decisions. However, there are essential risks, like usefulness and unnecessary complexity. For some applications, the DT may be a technology overkill. There are also concerns about the cost, security, privacy, and integration.

The development of modern electrical energy conversion systems is a matter of different subdisciplines with constantly augmenting applications in various manufacturing processes. It seems that the DT will be a considerable feature and a regular part of all electrical energy conversion systems soon. It is a question of what parts or subsystems to incorporate in the DT. In this paper the IR, the WT, the EV, and the telescope are defined as electrical energy conversion systems that convert electrical energy into mechanical energy (or vice versa, e.g. the WT). Simulation-mathematical modelling methods are commonly used in the research society. However, the DT as a physical replica of electrical energy conversion systems presents a new approach not only in modelling but also in optimization, maintenance and diagnostics, control, and in many other services.

For maximum performance, the DT needs to have a specific algorithm to be characterized in virtual assets. Big data from sensors need algorithms with self-learning ability, such as the NN and fuzzy logic to create a data analysis.

The flow for the effective development of a digital replica of an electrical energy conversion system is similar in all design tools. In summary, the following is required for making a precise simulation:

- precision (the level of details);

- data acquisition and validation;

- data model;

- synchronization.

The DT has precision requirements, setting the level of details for specific DT tasks to make it realistic and efficient for execution. Both - visualization and process flow precision - should be taken into consideration. The import and analysis of data received from the sensors of the monitoring system to enable correct data flow from the source equipment should be activated and used in the system. The Data Model and format merged with the data received from different sources and assets of the system is required, both for real-time and historical data. The data flow and type should be the same between the virtual and real worlds, the system should be connected via a telemetry middle layer platform. 


\section{ACKNOWLEDGEMENTS}

The research was supported by the Estonian Research Council under the grant PSG453 "Digital twin for pro- pulsion drive of autonomous electric vehicle". The publication costs of this paper were covered by the Estonian Academy of Sciences.
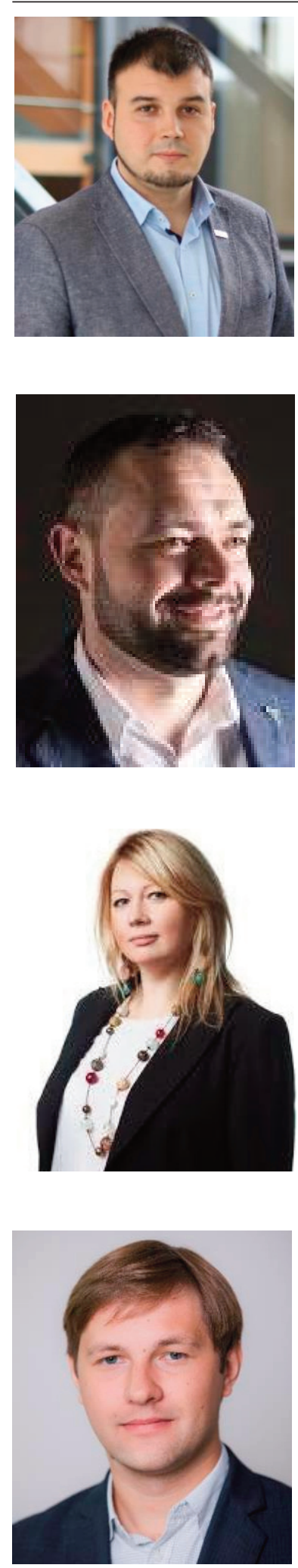

Anton Rassõlkin (PhD) is currently Professor in Mechatronics at the School of Engineering of the Department of Electrical Power Engineering and Mechatronics at Tallinn University of Technology. He also serves as Visiting Professor at ITMO University (St Petersburg, Russia) and as Visiting Professor at Silesian University of Technology (Gliwice, Poland). A. Rassõlkin's main research interests include mechatronics and electrical drives, with particular focus on electric transportation, and autonomous vehicles. He is a senior member of IEEE and a member of the Estonian Society of Moritz Hermann Jacobi.

Tamás Orosz (PhD) is currently Postdoctoral Researcher at the Department of Theory of Electrical Engineering at the University of West Bohemia (Pilsen, Czech Republic). He has previously worked as a software developer and an electrical machine designer. T. Orosz's research interests include robust design optimization and numerical modelling of electrical machines, as well as optimization implementation. He is a contributor to open software development projects, in particular the development of the robust design optimization framework Artap (http://www.agros2d.org/artap/).

Galina Lvovna Demidova (PhD) is currently Associate Professor at the Faculty of Control Systems and Robotics at ITMO University (St Petersburg, Russia). She has conducted more than 20 research and development projects dealing with control systems in digital electric power drives for tracking telescopes. G. L. Demidova has authored or co-authored more than 50 conference and journal papers. She has been organizer of IEEE Conference and co-guest editor of several IEEE special issues. G. L. Demidova is a senior member of IEEE.

Vladimir Kuts (PhD) holds the position of Head of Industrial Virtual and Augmented Reality Laboratory (www.ivar.ttu.ee) at the Department of Mechanical and Industrial Engineering at Tallinn University of Technology. His main research interests include Industrial Digital Twins synchronized with the real industrial equipment (such as robots), as well as usage of Virtual Reality technologies for validation of human-robot interaction standards. 

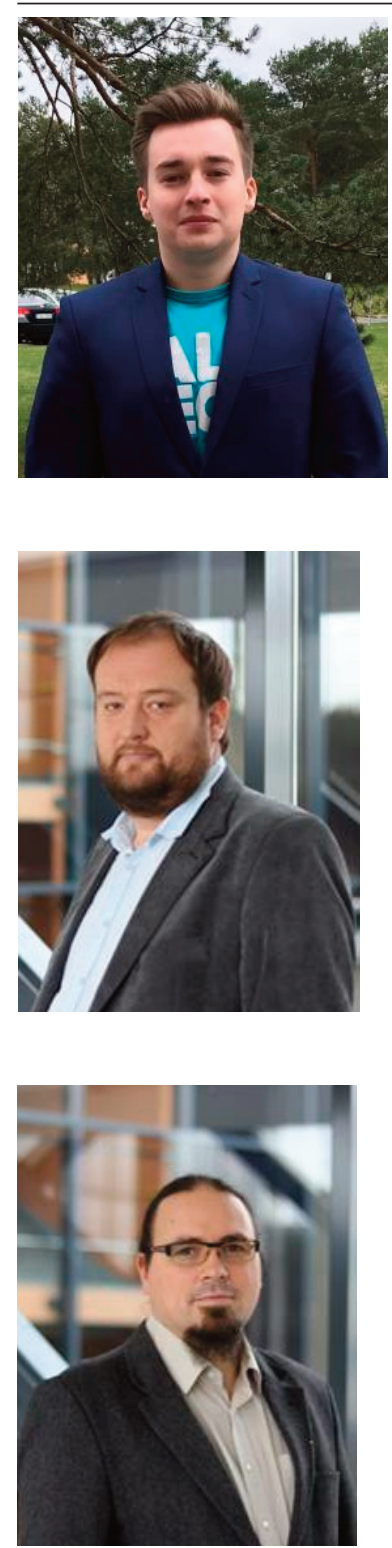

Ants Kallaste (PhD) is currently Professor of Electrical Machines at the Department of Electrical Power Engineering and Mechatronics at Tallinn University of Technology. Additionally, he holds the position of Head of Electrical Machines Research Group at Tallinn University of Technology. Besides research activities, A. Kallaste is involved in expertise and consultations for private companies in the field of electrical machines, drives, and their diagnostics. He is a member of IEEE since 2013 and a member of the Estonian Society of Moritz Hermann Jacobi.

\section{REFERENCES}

1. Weyer, S., Schmitt, M., Ohmer, M., and Gorecky, D. Towards industry 4.0-standardization as the crucial challenge for highlymodular, multi-vendor production systems. IFAC-PapersOnLine, 2015, 48(3), 579-584.

2. Li, Q., Jiang, H., Tang, Q., Chen, Y., Li, J., and Zhou, J. Smart manufacturing standardization: reference model and standards framework. In OTM Confederated International Conferences "On the Move to Meaningful Internet Systems", October 24-28, 2016, Rhodes, Greece. Lecture Notes in Computer Science, Vol. 10034, Springer, Cham, 2016, 16-25.

3. DIN: A collection of standards concerning Industry 4.0. https://www.din.de/en/innovation-and-research/industry-4-0/

4. Ghobakhloo, M. The future of manufacturing industry: a strategic roadmap toward industry 4.0. J. Manuf. Technol. Manag., 2018, 29(6), 910-936.
5. Stock, T. and Seliger, G. Opportunities of sustainable manufacturing in industry 4.0. Procedia CIRP, 2016, 40, 536-541.

6. El Saddik, A. Digital twins: the convergence of multimedia technologies. IEEE MultiMedia, 2018, 25(2), 87-92.

7. Sharma, M. and George, J. Digital twin in the automotive industry: driving physical-digital convergence. 2018. https://www.tcs.com/content/dam/tcs/pdf/Industries/manu facturing/abstract/industry-4-0-and-digital-twin.pdf

8. Tao, F. and Zhang, M. Digital twin shop-floor: a new shopfloor paradigm towards smart manufacturing. IEEE Access, 2017, 5, 20418-20427.

9. Grieves, M. and Vickers, J. Digital twin: mitigating unpredictable, undesirable emergent behavior in complex systems. In Transdisciplinary Perspectives on Complex Systems (Kahlen, F. J., et al., eds). Springer, Cham, 2017, 85-113.

10. Barricelli, B. R., Casiraghi, E., and Fogli, D. A survey on digital twin: definitions, characteristics, applications, 
and design implications. IEEE Access, 2019, 7, 167653167671.

11. Rosen, R., von Wichert, G., Lo, G., and Bettenhausen, K. D. About the importance of autonomy and digital twins for the future of manufacturing. IFAC-PapersOnLine, 2015, 48(3), $567-572$.

12. Weyer, S., Meyer, T., Ohmer, M., Gorecky, D., and Zuhlke, D. Future modeling and simulation of CPS-based factories: an example from the automotive industry. IFACPapersOnLine, 2016, 49(31), 97-102.

13. Orosz, T. Evolution and modern approaches of the power transformer cost optimization methods. Periodica Polytechnica Electrical Engineering and Computer Science, 2019, 63(1), 37-50.

14. Abetti, P., Cuthbertson, W., and Williams, S. Philosophy of applying digital computers to the design of electric apparatus. In Transactions of the American Institute of Electrical Engineers, Part I: Communication and Electronics, 1958, 77(3), 367-379.

15. Boschert, S. and Rosen, R. Digital twin-the simulation aspect. In Mechatronic Futures (Hehenberger, P., Bradley, D., eds). Springer, Cham, 2016, 59-74.

16. ANSYS: Engineering simulation \& 3D design software. http://www.ansys.com/

17. Zhang, L., Wang, W., and Shi, Y. Research on maximum power point tracking based on an improved fuzzy-PD dual-mode algorithm. In Proceedings of the 2017 10th International Congress on Image and Signal Processing, BioMedical Engineering and Informatics (CISP-BMEI), October 14-16, 2017, Shanghai, China. IEEE, 2017, 1-6.

18. Alexandrov, N. M., Hussaini, M. Y. (eds). Multidisciplinary Design Optimization: State of the Art. SIAM, Philadelphia, PA, 1997.

19. Karban, P., Mach, F., Kŭs, P., Pánek, D., and Doležel, I. Numerical solution of coupled problems using code Agros2D. Computing, 2013, 95(1), 381-408.

20. Karban, P., Pánek, D., Orosz, T., Petrášová, I., and Doležel, I. FEM based robust design optimization with Agros and Ārtap. Comput. Math. Appl., 2020. https://doi.org/10.1016/ j.camwa.2020.02.010

21. Tóth, B. Multi-field dual-mixed variational principles using non-symmetric stress field in linear elastodynamics. J. Elast., 2016, 122(1), 113-130.

22. Haag, S. and Anderl, R. Digital twin - proof of concept. Manuf. Lett., 2018, 15, 64-66.

23. Madni, A. M., Madni, C. C., and Lucero, S. D. Leveraging digital twin technology in model-based systems engineering. Systems, 2019, 7(1), 7.

24. Xu, G. and Xia, L. Short-term prediction of wind power based on adaptive LSTM. In Proceedings of the 2018 2nd IEEE Conference on Energy Internet and Energy System Integration (EI2), October 20-22, 2018, Beijing, China, 1-5.

25. Zhang, L. Specification and design of cyber physical systems based on system of systems engineering approach. In Proceedings of the 2018 17th International Symposium on Distributed Computing and Applications for Business Engineering and Science (DCABES), October 19-23, 2018, Wuxi, China, 300-303.

26. Peter, G. P. Calculations for short circuit withstand capability of a distribution transformer. Annals of Faculty Engineering Hunedoara. International Journal of Engineering, 2011, 9(3), 243-246.
27. Barrère, M., Hankin, C., Barboni, A., Zizzo, G., Boem, F., Maffeis, S., et al. CPS-MT: a real-time cyber-physical system monitoring tool for security research. In Proceedings of the 2018 IEEE 24th International Conference on Embedded and Real-Time Computing Systems and Applications (RTCSA), August 28-31, 2018, Hakodate, Japan, 240-241.

28. Schutzer, K., de Andrade Bertazzi, J., Sallati, C., Anderl, R., and Zancul, E. Contribution to the development of a digital twin based on product lifecycle to support the manufacturing process. Procedia CIRP, 2019, 84, 82-87.

29. Schluse, M. and Rossmann, J. From simulation to experimentable digital twins: simulation-based development and operation of complex technical systems. In Proceedings of the 2016 IEEE International Symposium on Systems Engineering (ISSE), October 3-5, 2016, Edinburgh, UK, $1-6$.

30. Iskhakova, A., Iskhakov, A., Meshcheryakov, R., and Jharko, E. Method of verification of robotic group agents in the conditions of communication facility suppression. IFACPapersOnLine, 2019, 52(13), 1397-1402.

31. He, B., Wang, S., and Liu, Y. Underactuated robotics: a review. Int. J. Adv. Robot. Syst., 2019, 16(4), 1729881419 862164.

32. Li, X., Luo, X., Wang, J., Zhu, Y., and Guan, X. Bearingbased formation control of networked robotic systems with parametric uncertainties. Neurocomputing, 2018, 306, 234 245.

33. Khalaji, A. K. Modeling and control of uncertain multibody wheeled robots. Multibody Syst. Dyn., 2019, 46(3), 257279.

34. International Federation of Robotics. https://ifr.org/

35. Kangru, T., Riives, J., Otto, T., Pohlak, M., and Mahmood, K. Intelligent decision making approach for performance evaluation of a robot-based manufacturing cell. In Proceedings of the ASME 2018 International Mechanical Engineering Congress and Exposition, November 9-15, 2018, Pittsburgh, PA, USA. https://doi.org/10.1115/IMECE2018-86666

36. Kuts, V., Sarkans, M., Otto, T., Tähemaa, T., and Bondarenko, Y. Digital twin: concept of hybrid programming for industrial robots-use case. In Proceedings of the ASME 2019 International Mechanical Engineering Congress and Exposition, November 11-14, 2019, Salt Lake City, UT, USA. https://doi.org/10.1115/IMECE2019-10583

37. Kuts, V., Otto, T., Tähemaa, T., Bukhari, K., and Pataraia, T. Adaptive industrial robots using machine vision. In Proceedings of the ASME 2018 International Mechanical Engineering Congress and Exposition, November 9-15, 2018, Pittsburgh, PA, USA. https://doi.org/10.1115/IMECE 2018-86720

38. Sell, R., Coatanea, E., and Christophe, F. Important aspects of early design in mechatronic. In Proceedings of the 6th International Conference of DAAAM Baltic Industrial Engineering, April 24-26, 2008, Tallinn, Estonia, 177-182.

39. Statista - The Statistics Portal for Market Data, Market Research and Market Studies. https://www.statista.com/

40. Estonian Road Administration, Traffic Safety Programme 2016-2025. https://www.mnt.ee/eng

41. Electric mobility in Germany. https://www.mnt.ee/eng

42. Autostat. https://eng.autostat.ru

43. Rassõlkin, A. and Vodovozov, V. A test bench to study propulsion drives of electric vehicles. In Proceedings of the International Conference-Workshop Compatibility in Power 
Electronics (CPE), June 5-7, 2013, Ljubljana, Slovenia. IEEE, 2013, 275-279.

44. Rassõlkin, A., Vaimann, T., Kallaste, A., and Kuts, V. Digital twin for propulsion drive of autonomous electric vehicle. In 2019 IEEE 60th International Scientific Conference on Power and Electrical Engineering of Riga Technical University (RTUCON), October 7-9, 2019, Riga, Latvia, 1-4.

45. Mi, C. and Masrur, M. A. Hybrid Electric Vehicles: Principles and Applications with Practical Perspectives, 2nd ed. John Wiley \& Sons, 2017.

46. Martínez, C. M., Hu, X., Cao, D., Velenis, E., Gao, B., and Wellers, M. Energy management in plug-in hybrid electric vehicles: recent progress and a connected vehicles perspective. IEEE Transactions on Vehicular Technology, 2016, 66(6), 4534-4549.

47. Senanayaka, J. S. L., Khang, H. V., and Robbersmyr, K. G. Multiple classifiers and data fusion for robust diagnosis of gearbox mixed faults. IEEE Transactions on Industrial Informatics, 2018, 15(8), 4569-4579.

48. Rassõlkin, A., Kallaste, A., and Vaimann, T. Dynamic control system for electric motor drive testing on the test bench. In Proceedings of the 2015 9th International Conference on Compatibility and Power Electronics (CPE), June 24-26, 2015, Costa da Caparica, Portugal. IEEE, 252257.

49. Kaban, S., Dong, Z., and Crawford, C. Performance modeling and benchmark analysis of an advanced 4WD series-parallel PHEV using dynamic programming. In Proceedings of the 2015 IEEE Vehicle Power and Propulsion Conference (VPPC), October 19-22, 2015, Montreal, QC, Canada, 698-704.

50. Rassõlkin, A. and Vodovozov, V. Experimental setup to explore the drives of battery electric vehicles. World Electr. Veh. J., 2013, 6(4), 1109-1114.

51. Sell, R., Aryassov, G., Petritshenko, A., and Kaeeli, M. Kinematics and dynamics of configurable wheel-leg. In Proceedings of the 8th International Conference of DAAAM Baltic Industrial Engineering, April 19-21, 2012, Tallinn, Estonia, 345-351.

52. Rassõlkin, A., Sell, R., and Leier, M. Development case study of the first Estonian self-driving car, ISEAUTO. Electrical, Control and Communication Engineering, 2018, 14(1), 81-88.

53. Kulik, E., Tran, X. T., and Anuchin, A. Estimation of the requirements for hybrid electric powertrain based on analysis of vehicle trajectory using GPS and accelerometer data. In Proceedings of the 2018 25th International Workshop on Electric Drives: Optimization in Control of Electric Drives (IWED), January 31-February 2, 2018 , Moscow, Russia. IEEE, 2018, 1-5.

54. Alam, K. M. and El Saddik, A. C2PS: a digital twin architecture reference model for the cloud-based cyberphysical systems. IEEE access, 2017, 5, 2050-2062.

55. Sell, R., Leier, M., Rassõlkin, A., and Ernits, J.-P. Selfdriving car ISEAUTO for research and education. In Proceedings of the 2018 19th International Conference on Research and Education in Mechatronics (REM), June 7-8, 2018, Delft, the Netherlands. IEEE, 2018, 111-116.

56. Daily, M., Medasani, S., Behringer, R., and Trivedi, M. Selfdriving cars. Computer, 2017, 50(12), 18-23.

57. Sell, R., Leier, M., Rassõlkin, A., and Ernits, J.-P. Autonomous last mile shuttle ISEAUTO for education and research. International Journal of Artificial Intelligence and Machine Learning (IJAIML), 2020, 10(1), 18-30.

58. Kalra, N. and Paddock, S. M. Driving to safety: how many miles of driving would it take to demonstrate autonomous vehicle reliability? Transp. Res. Part A Policy Pract., 2016, 94, 182-193.

59. Xu, Y., Zou, Y., and Sun, J. Accelerated testing for automated vehicles safety evaluation in cut-in scenarios based on importance sampling, genetic algorithm and simulation applications. J. Intell. Connect. Veh., 2018, 1(1), 1-4.

60. ISEAUTO Project. https://iseauto.taltech.ee/

61. Glaessgen, E. H. and Stargel, D. S. The digital twin paradigm for future NASA and US Air Force vehicles. In Proceedings of the 53rd AIAA/ASME/ASCE/AHS/ASC structures, structural dynamics and materials conference: Special session on the Digital Twin-, April 23-26, 2012, Honolulu, HI, USA. https://arc.aiaa.org/doi/abs/10.2514/ 6.2012-1818

62. Shubenkova, K., Valiev, A., Mukhametdinov, E., Shepelev, V., Tsiulin, S., and Reinau, K. H. Possibility of digital twins technology for improving efficiency of the branded service system. In Proceedings of the 2018 Global Smart Industry Conference (GloSIC), November 13-15, 2018, Chelyabinsk, Russia. IEEE, New York, NY, 2018, 1-7.

63. Brunner, P., Denk, F., Huber, W., and Kates, R. Virtual safety performance assessment for automated driving in complex urban traffic scenarios. In Proceedings of the 2019 IEEE Intelligent Transportation Systems Conference (ITSC), October 27-30, 2019, Auckland, New Zealand, 679-685.

64. Sesto, E. and Lipman, N. H. Wind energy in Europe. Wind Engineering, 1992, 16(1), 35-47.

65. Wind energy in Europe in 2019. https://windeurope.org/ about-wind/statistics/european/wind-energy-in-europe-in2019/

66. Electricity generation - Energy Charts. https://www.energycharts.de/energy pie.htm

67. Tarbimine ja tootmine (production and consumption) - Elering LIVE. https://dashboard.elering.ee/et/system/production-andconsumption/

68. Orlova, S., Rassõlkin, A., Kallaste, A., Vaimann, T., and Belahcen, A. Lifecycle analysis of different motors from the standpoint of environmental impact. Latvian Journal of Physics and Technical Sciences, 2016, 53(6), 37-46.

69. Sivalingam, K., Sepulveda, M., Spring, M., and Davies, P. A review and methodology development for remaining useful life prediction of offshore fixed and floating wind turbine power converter with digital twin technology perspective. In Proceedings of the 2018 2nd International Conference on Green Energy and Applications (ICGEA), March 24-26, 2018, Singapore. IEEE, 2018, 197-204.

70. Oñederra, O., Asensio, F. J., Eguia, P., Perea, E., Pujana, A., and Martinez, L. MV cable modeling for application in the digital twin of a windfarm. In Proceedings of the 2019 International Conference on Clean Electrical Power (ICCEP), July 2-4, 2019, Otranto, Italy. IEEE, New York, NY, 617-622.

71. Ebrahimi, A. Challenges of developing a digital twin model of renewable energy generators. In Proceedings of the 2019 IEEE 28th International Symposium on Industrial Electronics (ISIE), June 12-14, 2019, Vancouver, BC, Canada, 1059-1066.

72. Weigelt, M., Kink, J., Mayr, A., v. Lindenfels, J., Kuhl, A., and Franke, J. Digital twin of the linear winding process 
based on explicit finite element method. 2019 9th International Electric Drives Production Conference (EDPC), February 27, 2019, Esslingen, Germany, 1-7.

73. Fact sheet GE power \& water renewable energy https://www.ge.org (accessed 2020-03-16).

74. Digital twin software - enhance asset and process performance. https://www.seebo.com/digital-twin-software/

75. Digital manufacturing efficiency - PTC. https://www.ptc.com /en/solutions/digital-manufacturing/

76. Vaimann, T., Kudrjavtsev, O., Kilk, A., Kallaste, A., and Rassõlkin, A. Design and prototyping of directly driven outer rotor permanent magnet generator for small scale wind turbines. Adv. Electr. Electron. Eng., 2018, 16(3), 271-278.

77. Lukin, A., Demidova, G. L., Lukichev, D. V., Rassõlkin, A., Kallaste, A., Vaimann, T., et al. Experimental prototype of high-efficiency wind turbine based on magnus effect. In Proceedings of the 2020 27th International Workshop on Electric Drives: MPEI Department of Electric Drives 90th Anniversary (IWED), January 27-30, 2020, Moscow, Russia. IEEE, 2020, 1-6.

78. Tao, F., Cheng, J., Qi, Q., Zhang, M., Zhang, H., and Sui, F. Digital twin-driven product design, manufacturing and service with big data. Int. J. Adv. Manuf. Technol., 2018, 94, 3563-3576.

79. Tao, F., Zhang, M., Liu, Y., and Nee, A. Y. C. Digital twin driven prognostics and health management for complex equipment. CIRP Annals, 2018, 67(1), 169-172.

80. Pargmann, H., Euhausen, D., and Faber, R. Intelligent big data processing for wind farm monitoring and analysis based on cloud-technologies and digital twins: a quantitative approach. In Proceedings of the 2018 IEEE 3rd International Conference on Cloud Computing and Big Data Analysis (ICCCBDA), April 20-22, 2018, Chengolu, China, 233-237.

81. Imaie, E., Sheikholeslami, A., and Ahmadi Ahangar, R. Improving short-term wind power prediction with neural network and ICA algorithm and input feature selection. Journal of Advances in Computer Research, 2014, 5(3), 1334.

82. AhmadiAhangar, R., Rosin, A., Niaki, A. N., Palu, I., and Korõtko, T. A review on real-time simulation and analysis methods of microgrids. International Transactions on Electrical Energy Systems, 2019, 29(11), e12106.

83. Demidova, G. L., Lukichev, D. V., and Kuzin, A. Y. A genetic approach for auto-tuning of adaptive fuzzy PID control of a telescope's tracking system. Procedia Computer Science, 2019, 150, 495-502.

84. Chen, Z., Zhang, R., Chen, Z., Yang, S., and Hu, Q.-Q. Experiment and modal analysis on the primary mirror structure of space solar telescope. In Proceedings of the SPIE. Space Telescopes and Instrumentation I: Optical, Infrared, and Millimeter, May 24-31, 2006, Orlando, FL, USA, 62654B.

85. Kracht, K., v. Wagner, U., and Segert, T. Analysis of the vibration behavior of the Dobson space telescope. In Proceedings in Applied Mathematics and Mechanics (PAMM), 2007, 7(1), 4050035-4050036.

86. Bely, P. Y. (ed.). The Design and Construction of Large Optical Telescopes. Springer, New York, NY, 2003.

87. Withington, S. and Murphy, J. A. Modal analysis of partially coherent submillimeter-wave quasi-optical systems. IEEE Trans. Antennas Propag., 1998, 46(11), 1651-1659.
88. Aubrun, J.-N., Lorell, K. R., Havas, T. W., and Henninger, W. C. Performance analysis of the segment alignment control system for the ten meter telescope. Automatica, 1988, 24(4), 437-453.

89. Schipani, P. and Mancini, D. Modeling the VST telescope and the effect of the wind disturbance on its performance. IFAC Proceedings Volumes, 2002, 35(1), 179-185.

90. Lukichev, D. V., Demidova, G. L., and Brock, S. Comparison of adaptive fuzzy PID and ANFIS controllers for precision positioning of complex object with nonlinear disturbance - study and experiment. In Proceedings of the 2018 20th European Conference on Power Electronics and Applications (EPE'18 ECCE Europe), September 17-21, 2018, Riga, Latvia. IEEE, New York, NY, P.1-P.9.

91. Molfese, C., Schipani, P., Capaccioli, M., Sedmak, G., and D'Orsi, S. Survey telescope control electronics. In Proceedings of the 2008 International Symposium on Power Electronics, Electrical Drives, Automation and Motion, June 11-13, 2008, Ischia, Italy. IEEE, 2008, 523-527.

92. Costa, A., Sciacca, E., Vitello, F., Becciani, U., Massimino, P., Riggi, S., et al. An integrated workspace for the Cherenkov Telescope Array. Future Gener. Comput. Syst., 2019, 94, 811-819.

93. Kritzinger, W., Karner, M., Traar, G., Henjes, J., and Sihn, W. Digital Twin in manufacturing: a categorical literature review and classification. IFAC-PapersOnLine, 2018, 51(11), 1016-1022.

94. Hehenberger, P. and Bradley, D. Mechatronic Futures: Challenges and Solutions for Mechatronic Systems and their Designers. Springer, Cham, 2016.

95. Orosz, T., Sörés, P., Raisz, D., and Tamus, Z. Á. Analysis of the green power transition on optimal power transformer designs. Period. Polytech. Electr. Eng. Comput. Sci., 2015, 59(3), 125-131.

96. Dean, J. Pricing Policies for New Products. HBR Classics, 1976.

97. Wolpert, D. H. and Macready, W. G. No free lunch theorems for optimization. IEEE Trans. Evol. Comput., 1997, 1(1), 67-82.

98. Pánek, D., Orosz, T., and Karban, P. Artap: Robust design optimization framework for engineering applications. arXiv preprint arXiv:1912.11550, 2019.

99. Burnett, D., Thorp, J., Richards, D., Gorkovenko, K., and Murray-Rust, D. Digital twins as a resource for design research. In Proceedings of the 8th ACM International Symposium on Pervasive Displays, June 12-14, 2019, Palermo, Italy. ACM, New York, NY, 1-2.

100. Cerrone, A., Hochhalter, J. D., Heber, G., and Ingraffea, A. R. On the effects of modeling as-manufactured geometry: toward digital twin. Int. J. Aerosp. Eng., 2014(3), 439278.

101. Kuts, V., Modoni, G. E., Otto, T., Sacco, M., Tähemaa, T., Bondarenko, Y., et al. Synchronizing physical factory and its digital twin through an IioT middleware: a case study. Proc. Estonian Acad. Sci., 2019, 68(4), 364-370.

102. Vaimann, T., Rassõlkin, A., Kallaste, A., Pomarnacki, R., Belahcen, A., and Hyunh, V. K. Artificial intelligence in monitoring and diagnostics of electrical energy conversion systems. Proceeding of 27th International Workshop on Electric Drives (IWED2020), January 27-30, 2020, Moscow, Russia. IEEE, 2020, 9069566.

103. Zhang, M., Zuo, Y., and Tao, F. Equipment energy consumption management in digital twin shop-floor: a 
framework and potential applications. In Proceedings of the 2018 IEEE 15th International Conference on Networking, Sensing and Control (ICNSC), March 27-29, 2018, Zhuhai, China, 1-5.

104. Karanjkar, N., Joglekar, A., Mohanty, S., Prabhu, V., Raghunath, D., and Sundaresan, R. Digital twin for energy optimization in an SMT-PCB assembly line. In Proceedings of the 2018 IEEE International Conference on Internet of Things and Intelligence System (IOTAIS), November 1-3, 2018, Bali, Indonesia, 85-89.

105. Poór, P., Kuchtová, N., and Šimon, M. Machinery maintenance as part of facility management. Procedia Eng., 2014, 69, 1276-1280.

106. Kandukuri, S. T., Senanyaka, J. S. L., Hyunh, V. K., Robbersmyr, K. G., et al. A two-stage fault detection and classification scheme for electrical pitch drives in offshore wind farms using support vector machine. IEEE Trans. Ind. Appl., 2019, 55(5), 5109-5118.

107. Orłowska-Kowalska, T., Kowalski, C. T., and Dybkowski, M. Fault-diagnosis and fault-tolerant-control in industrial processesand electrical drives. In Advanced Control of Electrical Drives and Power Electronic Converters. Studies in Systems, Decision and Control, Vol. 75. Springer, Cham, 2017, 101-120.

108. Kabziński, J. (ed.). Advanced Control of Electrical Drives and Power Electronic Converters. Springer, 2017.

109. Vaimann, T. Diagnostics of induction machine rotor faults using analysis of stator signals. PhD thesis, Department of Electrical Engineering, Tallinn University of Technology, 2014.

110. Furtat, I. B. An algorithm to control nonlinear systems in perturbations and measurement noise. Autom. Remote Control, 2018, 79, 1207-1221.

111. Margun, A., Furtat, I., Bazylev, D., and Kremlev, A. Disturbance compensation and control algorithm with application for non-linear twin rotor MIMO system. In Mechatronics 2027. Advances in Intelligent Systems and Computing, Vol. 644. Springer, Cham, 2017, 428-435.

112. Furtat, I. B. and Fradkov, A. L. Robust control of multimachine power systems with compensation of disturbances. Int. J. Electr. Power Energy Syst., 2015, 73, 584-590.

113. Vas, P. Parameter Estimation, Condition Monitoring, and Diagnosis of Electrical Machines. Oxford University Press, 1993.

114. Thorsen, O. V. and Dalva, M. A survey of faults on induction motors in offshore oil industry, petrochemical industry, gas terminals, and oil refineries. IEEE Trans. Ind. Appl., 1995, 31(5), 1186-1196.

115. Petrov, A., Plokhov, I., Rassõlkin, A., Vaimann, T., Kallaste, A., and Belahcen, A. Adjusted electrical equivalent circuit model of induction motor with broken rotor bars and eccentricity faults. In Proceeding of the 2017 IEEE 11th International Symposium on Diagnostics for Electrical Machines, Power Electronics and Drives (SDEMPED), August 29-September 1, 2017, Tinos, Greece, 58-64.

116. Asad, B., Vaimann, T., Belahcen, A., Kallaste, A., Rassõlkin, A., and Iqbal, M. N. Broken rotor bar fault detection of the grid and inverter-fed induction motor by effective attenuation of the fundamental component, 2019. https://digital-library. theiet.org/content/journals/10.1049/iet-epa.2019.0350

117. Asad, B., Vaimann, T., Kallaste, A., Rassõlkin, A., Belahcen, A., and Iqbal, M. N. Improving legibility of motor current spectrum for broken rotor bars fault diagnostics. Electrical, Control and Communication Engineering, 2019, 15(1), 1-8.

118. Pando-Acedo, J., Rassõlkin, A., Lehikoinen, A., Vaimann, T., Kallaste, A., Romero-Cadaval, E., and Belahcen, A. Hybrid FEA-Simulink modelling of permanent magnet assisted synchronous reluctance motor with unbalanced magnet flux. In Proceedings of the 2019 IEEE 12th International Symposium on Diagnostics for Electrical Machines, Power Electronics and Drives (SDEMPED), August 27-30, 2019, Toulouse, France, 174-180.

119. Kudelina, K., Asad, B., Vaimann, T., Rassõlkin, A., Kallaste, A., and Lukichev, D. V. Main faults and diagnostic possibilities of BLDC motors. In Proceedings of the 2020 27th International Workshop on Electric Drives: MPEI Department of Electric Drives 90th Anniversary (IWED), January 27-30, 2020, Moscow, Russia. IEEE, 2020, 1-6.

120. Lee, K.-B. and Choi, U.-M. Faults and diagnosis systems in power converters. Advanced and Intelligent Control in Power Electronics and Drives. Studies in Computational Intelligence, Vol. 531. Springer, Cham, 2014, 143-178.

121. Yang, S., Xiang, D., Bryant, A., Mawby, P., Ran, L., and Tavner, P. Condition monitoring for device reliability in power electronic converters: a review. IEEE Trans. Power Electron., 2010, 25(11), 2734-2752.

122. Ruiming, F., Minling, W., Xinhua, G., Rongyan, S., Pengfei, S., et al. Identifying early defects of wind turbine based on SCADA data and dynamical network marker. Renew. Energ., 2020, 154, 625-635.

123. Kim, H.-C., Kim, M.-H., and Choe, D.-E. Structural health monitoring of towers and blades for floating offshore wind turbines using operational modal analysis and modal properties with numerical-sensor signals. Ocean Eng., 2019, 188, 106226.

124. Tao, F., Zhang, M., and Nee, A. Y. C. Digital Twin Driven Smart Manufacturing. Academic Press, 2019.

125. Lermer, M. and Reich, C. Creation of digital twins by combining fuzzy rules with artificial neural networks. In Proceedings of the IECON 2019 - 45th Annual Conference of the IEEE Industrial Electronics Society, October 14-17, 2019, Lisbon, Portugal, 5849-5854.

126. Kuts, V., Modoni, G. E., Terkaj, W., Tähemaa, T., Sacco, M., and Otto, T. Exploiting factory telemetry to support virtual reality simulation in robotics cell. In Proceedings of the International Conference on Augmented Reality, Virtual Reality and Computer Graphics, June 12-15, 2017, Ugento, Italy. Springer, Cham, 2017, 212-221.

127. Kuts, V., Sarkans, M., Otto, T., and Tähemaa, T. Collaborative work between human and industrial robot in manufacturing by advanced safety monitoring system. In Proceedings of the 28th DAAAM International Symposium on Intelligent Manufacturing and Automation, November 8-11, 2017, Zadar, Croatia. DAAAM International, Vienna, 2017, 0996-1001.

128. Shevtshenko, E., Karaulova, T., Igavens, M., Strods, G., Tandzegolskiene, I., Tutlys, V., et al. Dissemination of engineering education at schools and its adjustment to needs of enterprises. In Proceedings of the 28th DAAAM International Symposium on Intelligent Manufacturing and Automation, November 8-11, 2017, Zadar, Croatia. DAAAM International, Vienna, 2017, 44-53. 
129. Sell, R. Remote laboratory portal for robotic and embedded system experiments. International Journal of Online and Biomedical Engineering (iJOE), 2013, 9(S8), 23-26.

130. Mark, C. P. and Kamath, S. Review of active space debris removal methods. Space Policy, 2019, 47, 194-206.

131. Schildknecht, T., Hugentobler, U., and Verdun, A. Optical observations of space debris with the Zimmerwald 1-meter telescope. Adv. Space Res., 1997, 19(2), 221-228.

132. ITMO.NEWS. Watching the skies: Roscosmos installs a new set-up for monitoring space debris. https://news.itmo.ru/ en/science/cyberphysics/news/6502/
133. ROSCOSMOS. State Space Corporation. http://en. roscosmos.ru/

134. Arditti, D. Setting-up a small observatory: from concept to construction. Springer Science \& Business Media, New York, NY, 2007.

135. Gomez, E. L. and Fitzgerald, M. T. Robotic telescopes in education. Astronomical Review, 2017, 13(1), 28-68.

136. Bresina, J., Drummond, M., Swanson, K., and Edgington, W. Automated management and scheduling of remote automatic telescopes. Optical Astronomy from the Earth and Moon. ASP Conference Series, 1994, 55, 216-233.

\section{Digitaalsete kaksikute kasutamine elektrienergia muundussüsteemides - valitud juhtumianalüüside näitel}

\section{Anton Rassõlkin, Tamás Orosz, Galina Lvovna Demidova, Vladimir Kuts, Viktor Rjabtšikov, Toomas Vaimann ja Ants Kallaste}

Digitaalsete kaksikute rakendamine elektrienergia muundussüsteemides on tööstuse jaoks oluline ja lahendamist vajav probleem. Digitaalsed kaksikud võimaldavad ennustada keeruliste süsteemide tuleviku töötulemust, käitumist ja hooldusvajadust. Tänapäevased digitaalsed kaksikud ei ole kontseptuaalselt kasutatavad ainult füüsilise objekti emuleerimiseks ja simuleerimiseks, võttes arvesse ka arendusajalugu, vaid sisaldavad ka mahukat infot ühendatud tootjatelt ning teenustelt. Artiklis on esitletud antud hetke teaduskirjanduse analüüsi digitaalsete kaksikute uuenduslike rakendusvõimaluste kohta elektriinseneerias. Artikli eesmärgiks on anda ülevaade digitaalsete kaksikute edukast rakendamisest elektrienergia muundussüsteemides, nagu tööstusrobootikas ja tuulegeneraatorites, samuti arutleda sarnaste trendide võimalikust arengust elektertranspordis. On välja pakutud uuenduslikke kasutusvõimalusi näiteks teleskoopide täppisjuhtimises. Erilist tähelepanu pälvib digitaalsete kaksikute rakendamine elektrienergia muundussüsteemide rikkediagnostikas ja prognostikas. Digitaalsete kaksikute edukas rakendamine muundussüsteemide diagnostika ja seire valdkonnas võimaldab kuluefektiivset hooldust, eraldiseisvate seadmete ja süsteemide efektiivsemat kasutust ja väiksemat toormaterjalide ning inimtööjõu kasutusvajadust. Digitaalsete kaksikute kasutamise kohta elektrienergia muundussüsteemides on koostatud ka SWOT-analüüs, mille abil on võimalik hinnata uute tehnoloogiate kasutuselevõtu võimalusi ja valida parim tee arendustööde edasiseks jätkamiseks. 